\title{
An analytical study of critical heat flux in natural convective boiling in a vertical tube
}

\author{
Hasan M. M. Afroz ${ }^{1}$, M. A. Islam ${ }^{2}$ \\ ${ }^{1 *}$ Department of Mechanical Engineering, Dhaka University of Engineering\& Technology, BANGLADESH \\ ${ }^{2}$ Department of Mechanical Engineering, Bangladesh University of Engineering \& Technology, BANGLADESH \\ "Corresponding Author: e-mail: hafroz@yahoo.com, Tel +88-01818273067
}

\begin{abstract}
An analytical study is performed for the prediction of Critical Heat Flux (CHF) during natural convective boiling in a vertical uniformly heated tube, submerged in a saturated liquid bath, by a model where vapor forms a paraboloid under co-current flow situation. Mass, momentum and energy balances for the two-phase flow in the vertical tube are used to construct the model together with the criterion that the CHF is considered to be taking place at the exit of the heated tube when mass flux is maximum. About $300 \mathrm{CHF}$ data are predicted for saturated Water, R113 and R12 at different pressures of $\mathrm{P}=0.1$ to $3.0 \mathrm{MPa}$ for different tube geometries (diameter, $\mathrm{D}=1.12$ to $18.4 \mathrm{~mm}$, and heating length, $\mathrm{L}_{\mathrm{he}}=23$ to $960 \mathrm{~mm}$ ). The characteristics of CHF predicted by this model are explained and compared with similar existing experimental works. The effects of working fluids, working pressure, and tube geometry are mainly explained and compared to verify the basic performance of the model.
\end{abstract}

Keywords: Critical heat flux, natural convection, vertical tube, Analytical method, Prediction.

\section{Introduction}

Critical Heat Flux (CHF) in annular flow regime of natural convective boiling in a vertical tube is triggered when the liquid film disappears due to continuous evaporation and consequently the heated wall is exposed to vapor phase. In this case heat transfer from the heated wall is suddenly deteriorated and the wall temperature increases rapidly, which may cause significant damage to a system. So prediction of CHF is a prior design consideration regarding safety and economic optimization of various industrial heat transfer equipments such as superconductive devices, cooling of microelectric devices, nuclear reactor core, evaporator in a refrigeration or air conditioning unit and boiler of conventional power plant and nuclear power plant etc.

In the present days, enormous data and various empirical, semi-empirical correlations for CHF are available for each application. However, the applicable range of those correlations is geometrically and thermal-hydraulically confined to the experimental condition. The parametric trends are, however, identified from the data collected so far. A comprehensive theoretical model or correlation is yet to be developed so that it can be applied universally to predict CHF for various fluids at various thermalhydraulic and geometric conditions.

Katto (1978) developed a generalized correlation for the CHF during natural convective boiling in confined channels with the aid of dimensional analysis. In 1979, Katto and Kurosaka (1979) measured the CHF for three liquids (Water, Ethanol, and R113) except for cryogenic liquids and annular channels. They explained three characteristics CHF regimes and developed generalized correlations for two of the regimes. Monde and Yamaji (1990) measured CHF during the natural convective boiling in a vertical uniformly heated tube submerged in a saturated liquid. They used Water, R113 and R12 as working fluids and proposed two generalized correlations to predict CHF for two characteristic regimes. Monde et al. (1993) made an analytical study of the critical heat flux of a two phase thermosyphon, in which liquid and vapor form a countercurrent annular flow. They derived two correlations for two limiting conditions. Katto and Yokoya (1970) proposed a preliminary model describing the macrolayer dryout as the mechanism leading to CHF in pool boiling. Later, Haramura and Katto (1983) completed the model development by introducing the mechanism for macrolayer formation in both pool and flow boiling. 
CHF in annular film flow regime can be determined at the point where the processes of evaporation, deposition, and entrainment lead to a condition in which the film flow rate becomes zero. Analytical treatments of this type have been explored in depth by Whalley, Hewitt, and co-workers (Whalley et al., 1974a,b; Whalley, 1976; Govan et al., 1988). The results of these investigations indicate that this type of method can be used successfully to predict CHF conditions for forced-convective boiling in tubes, annuli, and rod bundles. Okawa et al. (2003) predicted CHF in annular flow using a film flow model. Their predicted results agree with the experimental data fairly well when the flow pattern at the onset of critical heat flux condition is considered annular flow.

From the above discussion it is clear that a very little analytical study on CHF of natural convective boiling have been carried out to obtain the fundamental design information necessary to apply the system as an efficient heat transfer device. Thus the present study has devoted to develop an analytical method to predict the CHF of natural convective boiling in vertical heated tubes submerged in a saturated liquid bath where vapor and liquid constitute a co-current flow.

\section{Analysis methodology}

\subsection{Model}

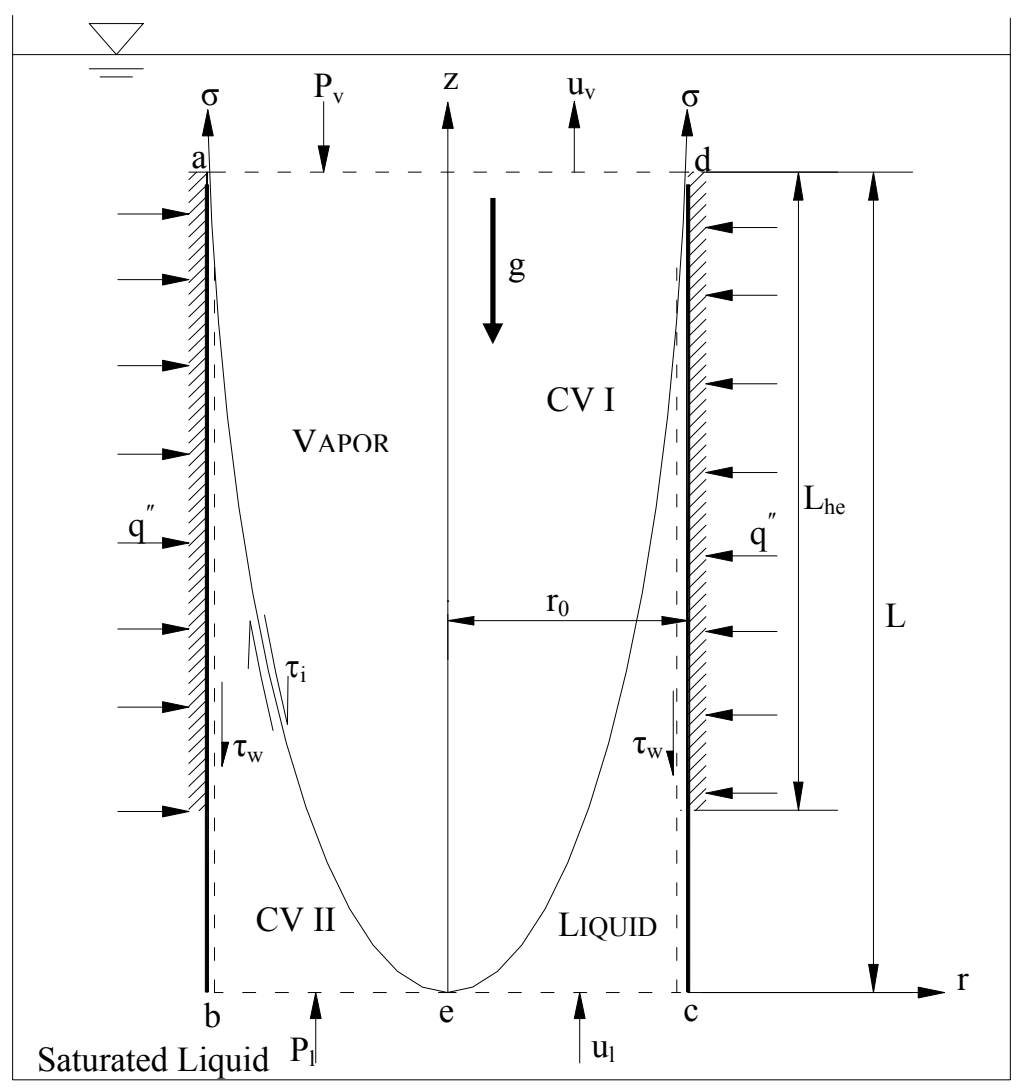

Figure 1. Idealized flow model of the analysis of CHF

An analytical study has been made for the prediction of CHF of natural convective boiling in a vertical uniformly heated tube, submerged in a saturated liquid bath where the saturated liquid enters the tube at the bottom and it vaporized through the heating wall and the liquid-vapor mixture flows upward due to buoyancy only. This analysis has been carried out by a flow model in which the CHF is assumed to occur under annular co-current flow of liquid and vapor. The proposed model assumes the flow situation of liquid and vapor just before the CHF point as shown in the Figure 1. The liquid-vapor interface of the annular flow is assumed as a smooth curve of parabolic shape defined by the Eq. (1) where the exponent ' $n$ ' is the profile index that gives the shape of the interface.

$$
\frac{\mathrm{z}}{\mathrm{L}}=\left(\frac{\mathrm{r}}{\mathrm{r}_{\mathrm{o}}}\right)^{\mathrm{n}} \text {, for } \mathrm{n} \geq 2
$$




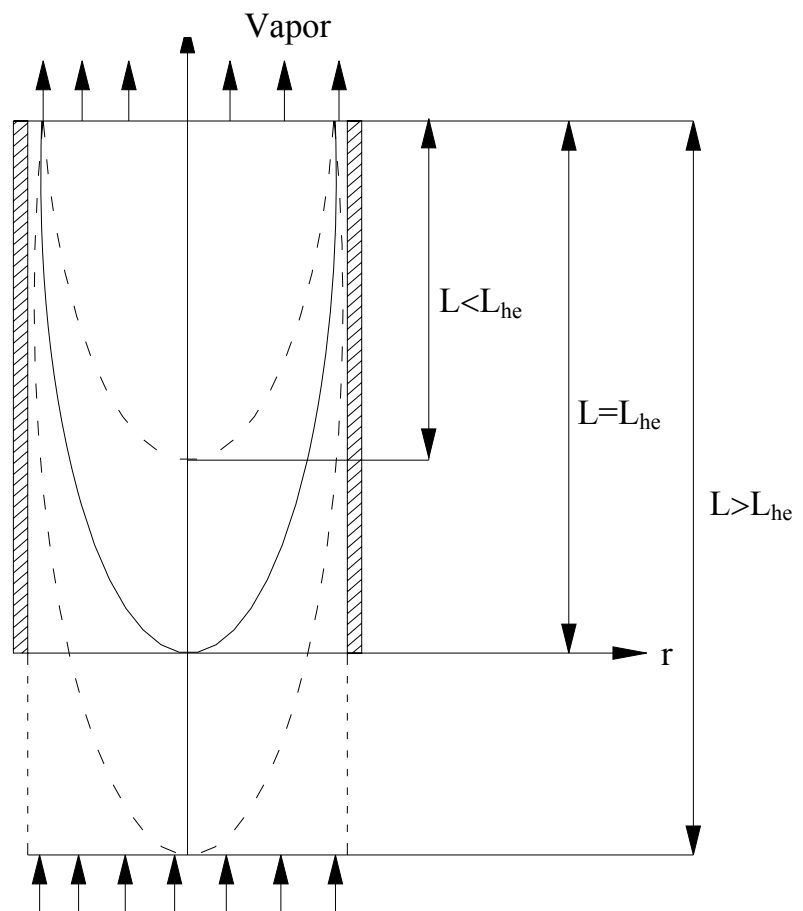

Liquid

Figure. 2 Liquid-vapor interface profile length variation

The profile length, L may vary in such a way that it may be greater than, less than or equal to the tube heating length, $\mathrm{L}_{\mathrm{he}}$ as shown in the Figure 2. For the annular concurrent flow, the CHF is occurred at the exit of the heated tube when the void fraction is unity. In addition to the above mentioned assumptions, both entrainment and deposition of liquid are ignored and the two phases are considered in local thermodynamic equilibrium and the flow is considered steady even though two-phase flow in the tube is oscillating as mentioned in the study by Monde and Yamaji (1990).

According to the Figure 1 the mass conservation for the control volume (I), containing vapor and control volume (II), containing liquid is given by Eq. (2)

$$
\int_{\text {CSI }} \rho \mathrm{udA}=\int_{\mathrm{CSII}} \rho \mathrm{udA}=0
$$

The momentum balance of the control volume (I) in the z- direction can be expressed by Eq.(3)

$$
-\int_{\mathrm{CVI}} \rho_{\mathrm{v}} \mathrm{gdV}+\int_{\mathrm{CSI}} \mathrm{PdA}-2 \pi \int_{0}^{\mathrm{L}} \mathrm{r}\left(\tau_{\mathrm{i}}\right)_{\mathrm{I}} \mathrm{dz}=\int_{\mathrm{CSI}}(\mathrm{Gu})_{\text {out }} \mathrm{dA}-\int_{\mathrm{CSI}}(\mathrm{Gu})_{\text {in }} \mathrm{dA}
$$

And the momentum balance of the control volume (II), in the $\mathrm{z}$ direction is expressed by Eq.(4)

$$
-\int_{\mathrm{CVII}} \rho_{\mathrm{I}} \mathrm{gdV}+\int_{\mathrm{CSII}} \mathrm{PdA}+2 \pi \int_{0}^{\mathrm{L}} \mathrm{r}\left(\tau_{\mathrm{i}}\right)_{\text {II }} \mathrm{dz}-\int_{0}^{\mathrm{L}} 2 \pi \mathrm{r}_{\mathrm{o}} \tau_{\mathrm{w}} \mathrm{dz}=\int_{\mathrm{CSII}}(\mathrm{Gu})_{\text {out }} \mathrm{dA}-\int_{\mathrm{CSII}}(\mathrm{Gu})_{\text {in }} \mathrm{dA}
$$

For steady flow, the interfacial shear forces must be balanced. Adding Eq. (3) and Eq. (4) the following relation, Eq. (5) for the overall momentum balance of the control volume abcd can be obtained.

$$
\mathrm{F}_{\mathrm{P}}-\mathrm{F}_{\mathrm{G}}-\mathrm{F}_{\mathrm{w}}-\mathrm{F}_{\mathrm{M}}=0
$$

Where,

$$
\mathrm{F}_{\mathrm{P}}=\left[\int_{\mathrm{CSI}} \mathrm{PdA}+\int_{\text {CSII }} \mathrm{PdA}\right]=\text { Pressure Force }
$$




$$
\begin{aligned}
& F_{G}=g\left[\int_{C V I} \rho_{v} d V+\int_{C V I I} \rho_{l} d V\right]=\text { Gravity Force } \\
& F_{M}=\int_{C S I}(G u)_{\text {out }} d A-\int_{C S I I}(G u)_{\text {in }} d A=\text { Rate of Change of Momentum } \\
& F_{\mathrm{W}}=\int_{0}^{\mathrm{L}} 2 \pi r_{\mathrm{o}} \tau_{\mathrm{W}} \mathrm{dz} \quad=\text { Wall Friction Force }
\end{aligned}
$$

Through proper mathematical manipulation and suitable inlet velocity profile considerations (Afroz, 2004), the above forces can be simplified as the Eqs. (6)-(9)

$$
\begin{aligned}
& \mathrm{F}_{\mathrm{P}}=2 \pi \mathrm{r}_{\mathrm{o}} \sigma+\rho_{1} \mathrm{~g} \pi \mathrm{r}_{\mathrm{o}}^{2} \mathrm{~L} \\
& \mathrm{~F}_{\mathrm{G}}=\pi \mathrm{r}_{\mathrm{o}}^{2} \mathrm{gL}\left[\left(\rho_{\mathrm{v}}-\rho_{\mathrm{l}}\right) \frac{\mathrm{n}}{\mathrm{n}+2}+\rho_{\mathrm{l}}\right] \\
& \mathrm{F}_{\mathrm{M}}=\left(\frac{50 \pi}{49 \rho_{\mathrm{v}}}-\frac{25 \pi}{21 \rho_{1}}\right) \mathrm{r}_{\mathrm{o}}^{2} \mathrm{G}^{2} \\
& \mathrm{~F}_{\mathrm{w}}=\frac{\pi \mathrm{r}_{0} \mathrm{G}^{2} \mathrm{~L}}{\rho_{1}} \mathrm{I}
\end{aligned}
$$

Here,

$$
\begin{array}{rlr}
I=\left[\int_{0}^{1-L^{+}} \frac{C_{f w}}{\left\{1-\left(z^{+}\right)^{2 / n}\right\}^{4}} d z^{+}+\int_{1-L^{+}}^{1} \frac{C_{f w}\left(1-z^{+}\right)^{2}}{\left\{1-\left(1-L^{+}\right)^{2 / n}\right\}^{2} L^{+2} \cdot\left\{1-\left(z^{+}\right)^{2 / n}\right\}^{2}} d z^{+}\right], & \text {for } L^{+}<1 \\
& =\int_{0}^{1} C_{f w} \frac{\left(1-z^{+}\right)^{2}}{\left[1-\left(z^{+}\right)^{2 / n}\right]^{2}} d^{+}, & \text {for } L^{+}=1 \\
& =\int_{0}^{1} C_{f w} \frac{\left(1-z^{+}\right)^{2}}{L^{+2}\left[1-\left(z^{+}\right)^{2 / n}\right]^{2}} d z^{+}, & \text {for } L^{+}>1
\end{array}
$$

And $\mathrm{C}_{\mathrm{fw}}$, the wall friction factor, can be obtained from the equations provided by Wallis (1969) in the laminar and turbulent flow regions and by Monde (1996) in the transition regions that are shown in the following Eqs. (10)-(12).

$$
\begin{gathered}
\mathrm{C}_{\mathrm{fw}}=\frac{16}{\mathrm{Re}_{1}}, \quad \text { When, } \operatorname{Re}_{1} \leq 160 \\
\mathrm{C}_{\mathrm{fw}}=\operatorname{Exp}\left[5.48616-2.10284 \log _{\mathrm{e}}\left(\operatorname{Re}_{1}\right)+0.11855\left(\log _{\mathrm{e}} \operatorname{Re}_{1}\right)^{2}\right. \\
\left.-1.30035 \times 10^{-3}\left(\log _{\mathrm{e}} \operatorname{Re}_{1}\right)^{3}\right], \quad \text { when, } 160 \leq \operatorname{Re}_{1} \leq 10^{4} \\
\mathrm{C}_{\mathrm{fw}}=0.079 / \operatorname{Re}_{1}^{-0.25}, \quad \text { When, } \quad \operatorname{Re}_{1} \geq 10^{4}
\end{gathered}
$$

From the Eqs. (5-9), final form of the momentum equation can be written as the Eq. (13). 


$$
\therefore \mathrm{F}_{1}(\mathrm{G}, \mathrm{L})=\frac{\pi \mathrm{r}_{0} \mathrm{G}^{2} \mathrm{~L}}{\rho_{\mathrm{L}}} \mathrm{I}+\left(\frac{50 \pi}{49 \rho_{\mathrm{v}}}-\frac{25 \pi}{21 \rho_{\mathrm{l}}}\right) \mathrm{r}_{\mathrm{o}}^{2} \mathrm{G}^{2}+\pi \mathrm{r}_{\mathrm{o}}^{2} \mathrm{gL}\left(\rho_{\mathrm{v}}-\rho_{\mathrm{l}}\right) \frac{\mathrm{n}}{\mathrm{n}+2}+2 \pi \mathrm{r}_{\mathrm{o}} \sigma=0
$$

At the CHF, q fixes the profile length, L maximizing the mass flux, G.

So, for maximum $\mathrm{G}, \quad \frac{\partial \mathrm{G}}{\partial \mathrm{L}}=0$

According to Euler's theorem, Eq.(13) can be written as-

$$
\begin{aligned}
& \frac{\partial \mathrm{F}_{1}}{\partial \mathrm{G}} \partial \mathrm{G}+\frac{\partial \mathrm{F}_{1}}{\partial \mathrm{L}} \partial \mathrm{L}=0 \\
\Rightarrow & \frac{\partial \mathrm{F}_{1}}{\partial \mathrm{G}} \cdot \frac{\partial \mathrm{G}}{\partial \mathrm{L}}+\frac{\partial \mathrm{F}_{1}}{\partial \mathrm{L}}=0
\end{aligned}
$$

Hence, for maximum G, Eq. (14) becomes-

$$
\begin{gathered}
\frac{\partial \mathrm{F}_{1}}{\partial \mathrm{L}}=0=\mathrm{F}_{2}(\mathrm{G}, \mathrm{L}), \text { (Let) } \\
\Rightarrow \mathrm{F}_{2}(\mathrm{G}, \mathrm{L})=\frac{\pi \mathrm{r}_{\mathrm{o}} \mathrm{G}^{2}}{\rho_{\mathrm{l}}}\left(\mathrm{L} \frac{\partial \mathrm{I}}{\partial \mathrm{L}}+\mathrm{I}\right)+\pi \mathrm{r}_{\mathrm{o}}^{2} \mathrm{~g}\left(\rho_{\mathrm{v}}-\rho_{1}\right) \frac{\mathrm{n}}{\mathrm{n}+2}=0
\end{gathered}
$$

Solution of the simultaneous Eqs. (13) and (15) will result the maximum G.

In the annular flow regime of the boiling inside vertical tube, evaporation, entrainment, and deposition may be happened. In our analysis, we did not consider entrainment and deposition. Only evaporation is considered. The CHF is determined according to the heat balance between the heat used for evaporating liquid and supplied wall flux.

Heat transfer rate due to evaporation $=\frac{G \pi \mathrm{D}^{2}}{4} \mathrm{H}_{\mathrm{lg}}$

Heat supplied rate from the surface of the wall $=\mathrm{q} \pi \mathrm{DL}$ he

So the heat balance become, $q=\frac{\mathrm{H}_{\mathrm{lg}} \mathrm{DG}}{4 \mathrm{~L}_{\mathrm{he}}}$

At the critical heat flux situation the mass flux will be maximum so the critical heat flux becomes as the Eq.(16)

$$
\mathrm{q}_{\mathrm{co}}=\frac{\mathrm{H}_{\mathrm{lg}} \mathrm{DG}_{\mathrm{max}}}{4 \mathrm{~L}_{\mathrm{he}}}
$$

\subsection{Solution Procedure}

Knowing the properties of fluid and geometric parameters of the tube, the model can be solved as follows-

(1) An initial guess is made for the mass flux, $G$ and the profile length, $L$

(2) The values of the functions $F_{1}(G, L)$ and $F_{2}(G, L)$ from the Eqs. (13) and (15) are computed for a particular tube geometry, working fluid and working condition.

(3) Using iterative technique together with the condition $\mathrm{ABS}\left(\mathrm{F}_{1}(\mathrm{G}, \mathrm{L})-\mathrm{F}_{2}(\mathrm{G}, \mathrm{L})\right) \leq 0.00005$ the solution values of $\mathrm{G}$ and $\mathrm{L}$ are obtained.

(4) The obtained solution value of the $G$ will be the maximum mass flux, $G_{\max }$ for a particular tube geometry and thermal-hydraulic condition of the working fluid.

(5) The value of $G_{\max }$ is used to calculate $q_{c o}$ from the Eq. (16).

\subsection{Analysis range of the different parameters}

CHF data of natural convective boiling in vertical heated tube has been calculated by varying several parameters namely, working fluid, working pressure, tube diameter, and tube heating length, and heating length and diameter ratio. Different values of these parameters are categorically given in the Table 1 which is identical with the experimental ranges of Monde and Yamaji (1990). 
Table 1 Analysis range of the different parameters

\begin{tabular}{|c|c|c|c|c|c|}
\hline $\begin{array}{c}\text { Working } \\
\text { Fluid }\end{array}$ & $\begin{array}{c}\text { Pressure } \\
(\mathrm{MPa})\end{array}$ & $\begin{array}{c}\text { Heating } \\
\text { Length }(\mathrm{mm})\end{array}$ & $\begin{array}{c}\text { Tube Diameter, } \\
\mathrm{D}=2 \mathrm{r}_{\mathrm{o}}(\mathrm{mm})\end{array}$ & $\mathrm{L}_{\mathrm{he}} / \mathrm{D}$ & $\rho_{\mathrm{v}} / \rho_{\mathrm{l}}$ \\
\hline R113 & $0.1-0.3$ & $23-960$ & $1.12-18.4$ & $5-857$ & $4.95 \times 10^{-3}-0.0147$ \\
\hline R12 & $0.793-2.907$ & $23-960$ & $1.12-18.4$ & $5-857$ & $0.0348-0.2095$ \\
\hline Water & 0.1 & $23-960$ & $1.12-18.4$ & $5-857$ & $6.22 \times 10^{-4}$ \\
\hline
\end{tabular}

\section{Results and Discussion}

Using the model described above many CHF data have been calculated by varying the tube geometry and thermal-hydraulic conditions of the various working fluids, with a view to evaluating the effects of various parameters on CHF, making comparison and evaluating performance of the model.

\subsection{Characteristics}

Figure 3 has been constructed with the present analytical data to explain the basic CHF characteristics of different working fluids and Figure 4 representing the experimental data (Monde and Yamaji (1990)) has been constructed to compare the characteristics of CHF with the analytical ones. Figure 3 represents all the CHF data plotted against the density ratio $\left(\rho_{\mathrm{v}} / \rho_{\mathrm{l}}\right)$. The solid line for each working fluid as shown in this figure is the Kutateladze correlation, Eq. (17) for predicting the CHF in an ordinary saturated pool boiling.

$$
\mathrm{Ku}=\frac{\mathrm{q}_{\mathrm{co}} / \rho_{\mathrm{v}} \mathrm{H}_{\mathrm{lg}}}{\sqrt[4]{\sigma \mathrm{g}\left(\rho_{1}-\rho_{\mathrm{v}}\right) / \rho_{\mathrm{v}}^{2}}}=0.16
$$

Where $\mathrm{Ku}$ is called the Kutateladze number.

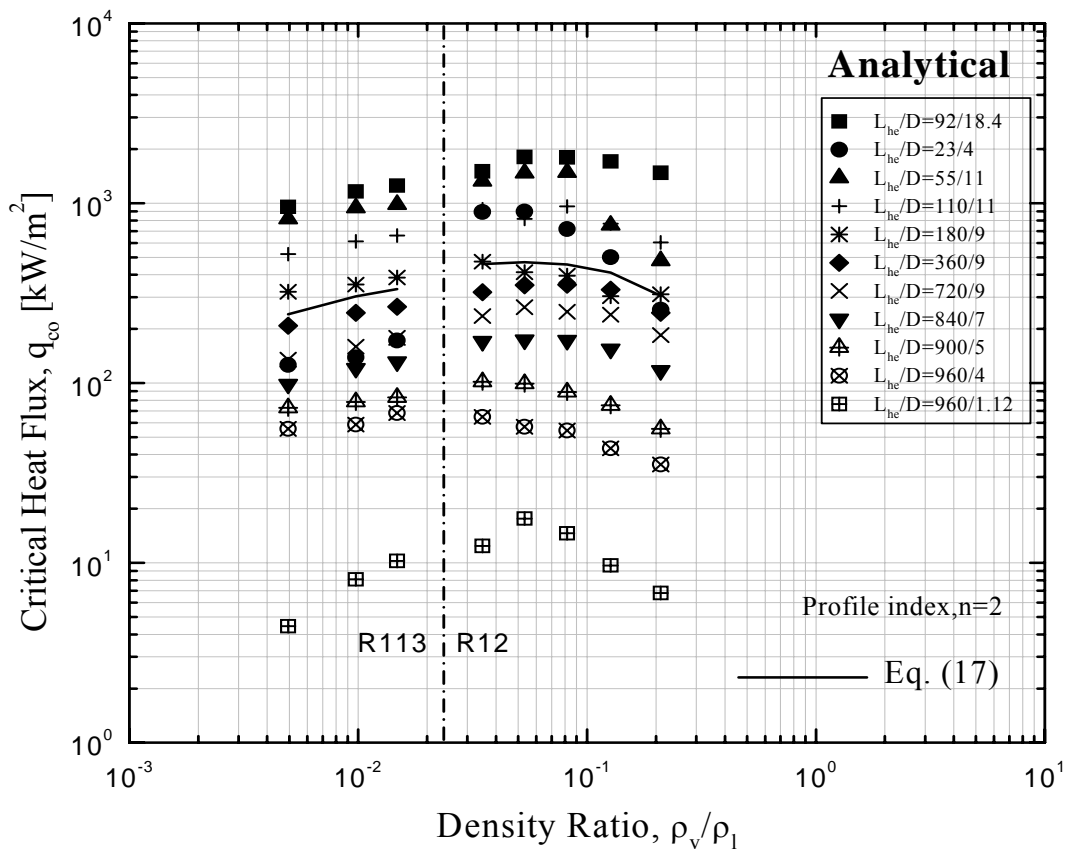

Figure 3. Characteristics of the CHF in natural convective boiling of saturated liquid in vertical tubes (analytical) 


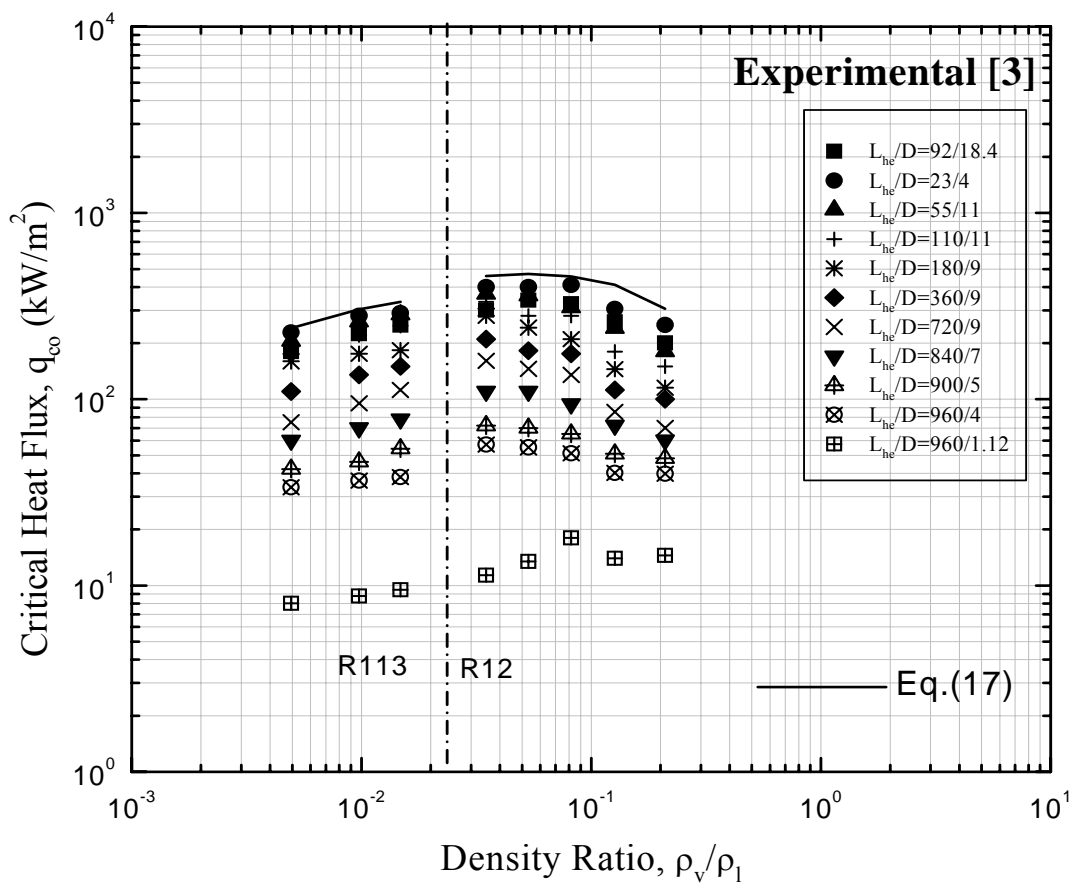

Figure 4. Characteristics of the CHF of natural convective boiling of saturated liquid in vertical tubes (Experimental, Monde and Yamaji (1990))

Each of the symbols in Figure 3 represents a CHF data for a particular combination of heating length and diameter of the vertical tube. The CHF in a vertical tube basically depends on the ratio $L_{h e} / D$ and $\rho_{v} / \rho_{1}$ and its character has a tendency similar to Kutateladze's prediction for saturated pool boiling. The CHF of the present analysis should be smaller than the Kutateladze's prediction by Eq. (17) because this analysis is done for the boiling in a narrow confine of a tube whereas Eq. (17) is for pool boiling. But Figure 3 shows that some of the CHF for smaller $L_{h e} / D$ are higher than the Kutateladze's prediction and this may be due to the choice of the profile index and other assumptions that are considered for the simplification of this analysis. For Figure 3 we have used profile index, $\mathrm{n}=2$ which may not be suitable for smaller $\mathrm{L}_{\mathrm{he}} / \mathrm{D}$. Effects of profile index on CHF prediction by this model is discussed in a later section.

For the same value of $\mathrm{L}_{\mathrm{he}} / \mathrm{D}$, the CHF increases with an increase of $\rho_{\mathrm{v}} / \rho_{1}$ for R113, while it decreases for R12. This is because of the working pressures chosen in this study such that the reduced pressure, $P_{r}$, is in the range of 0.192 to 0.703 for $R 12$ and $P_{r}<<$ 0.192 for R113. It is well known that the CHF increases with $P_{r}$ and becomes maximum at a working pressure of about $P_{c} / 3$ (i.e. $\mathrm{P}_{\mathrm{r}}=1 / 3$ ), beyond which it decreases continuously (Stephan, 1987). As $\mathrm{P}_{\mathrm{r}}$ increases with $\rho_{\mathrm{v}} / \rho_{\mathrm{l}}$, the CHF as shown in Figure 3 is obtained. It is worth mentioning that for a constant $\rho_{\mathrm{v}} / \rho_{\mathrm{l}}$, the CHF increases with an increase in tube diameter for a fixed length of the tube and decreases with an increase in tube length for a constant tube diameter.

The Characteristics of the calculated CHF values with respect to different $\mathrm{L}_{\mathrm{he}} / \mathrm{D}$ and $\rho_{\mathrm{v}} / \rho_{1}$ of the Figure 3 show similar tendency of the experimentally measured CHF values by Monde and Yamaji (1990) as shown in the Figure 4.

Influences of tube heating length and diameter ratio, $\mathrm{L}_{\mathrm{he}} / \mathrm{D}$ on CHF are shown in the Figures 5, 6 and 7 where different symbols are for different working pressures. For all the working fluids, CHF decreases as the $\mathrm{L}_{\mathrm{he}} / \mathrm{D}$ increases and the reasons are clearly discussed in (Katto and Kurosaka, 1979; Monde and Yamaji, 1990; Monde et al., 1993). For all three working fluids, present model shows over prediction of the experimental results of Monde and Yamaji (1990). 


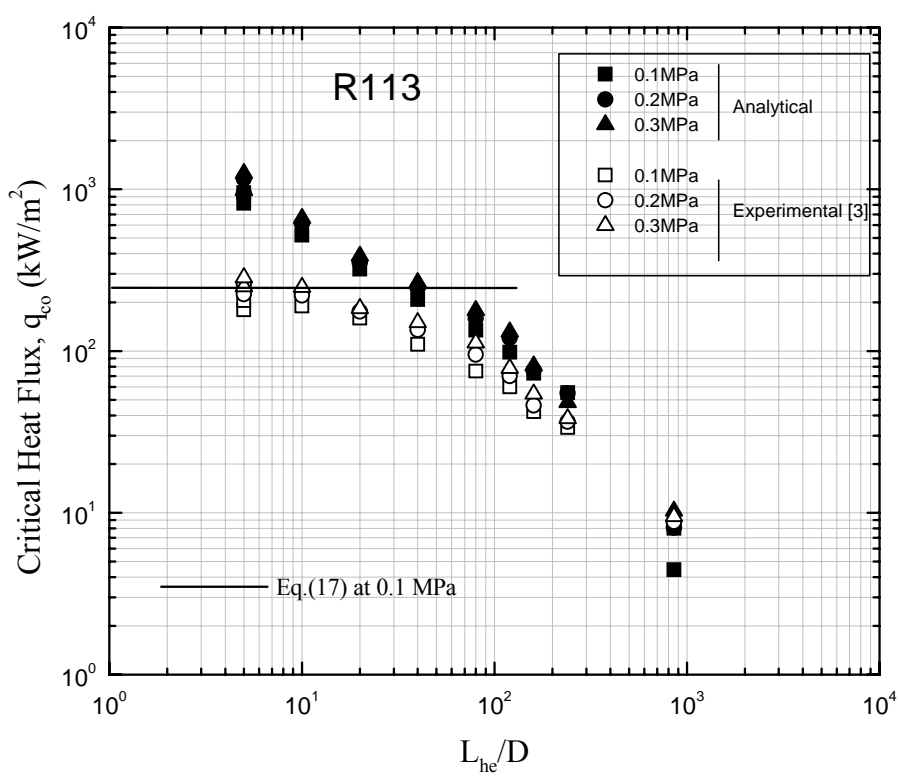

Figure 5. Effect of $\mathrm{L}_{\mathrm{he}} / \mathrm{D}$ on CHF for R113

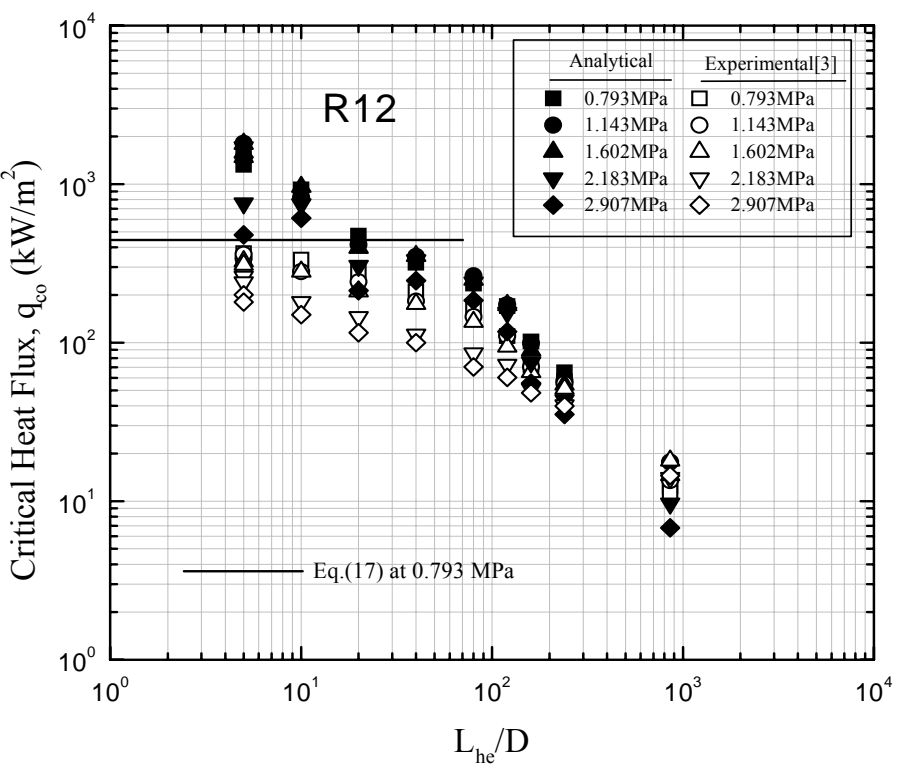

Figure 6. Effect of $\mathrm{L}_{\mathrm{he}} / \mathrm{D}$ on CHF for R12

\subsection{Effects of interface profile shape}

The liquid-vapor interface of the annular flow in this analysis is assumed a paraboloid formed by Eq. (1) and Figure 8 shows the change of the shape of the interface with the change of profile index, $\mathrm{n}$. For a fixed value of $\mathrm{z}$ and $\mathrm{L}$, where $\mathrm{z} \leq \mathrm{L}$, the void fraction increases with the increase of $\mathrm{n}$ because the interface shape becomes wider at that $\mathrm{z}$ location for higher $\mathrm{n}$. Figure 9 shows the variation of CHF with the profile index $n$ for the working fluid R113 at a fixed $\mathrm{L}_{\mathrm{he}} / \mathrm{D}$. It shows that with the increase of $\mathrm{n}$ the CHF decreases because the void fraction increases with the $\mathrm{n}$. At higher $\mathrm{n}$ the analytical CHF approaches to the experimental values but Figure 10 shows that the change of the CHF is significant upto $n=8$ and then further increase of $n$ has very little effect on CHF. For the present analysis, the profile index is assumed to be 2 and the profile looks like the Figure 1 but in actual case the profile shape is always changing with respect to the change of the tube dimensions and thermal-hydraulic conditions. Further analysis 
may be required to obtain an expression of ' $n$ ' incorporating the effects of tube geometric parameters and thermal-hydraulic conditions.

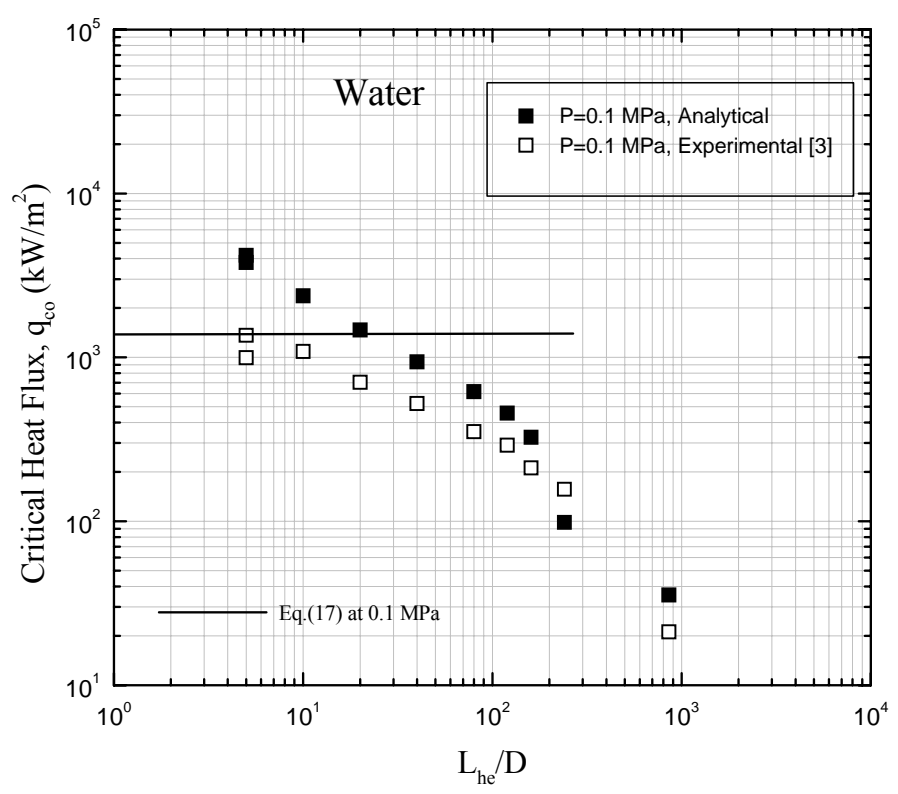

Figure 7. Effect of $\mathrm{L}_{\mathrm{he}} / \mathrm{D}$ on $\mathrm{CHF}$ for Water

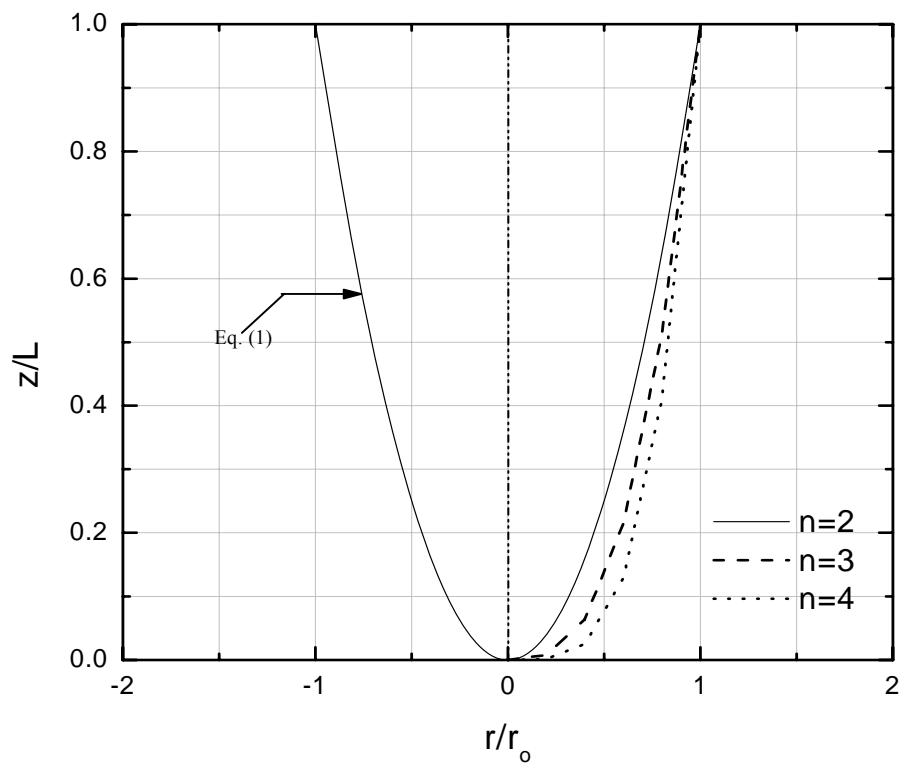

Figure 8. Effects of profile index ' $n$ ' on the liquid-vapor interface shape 


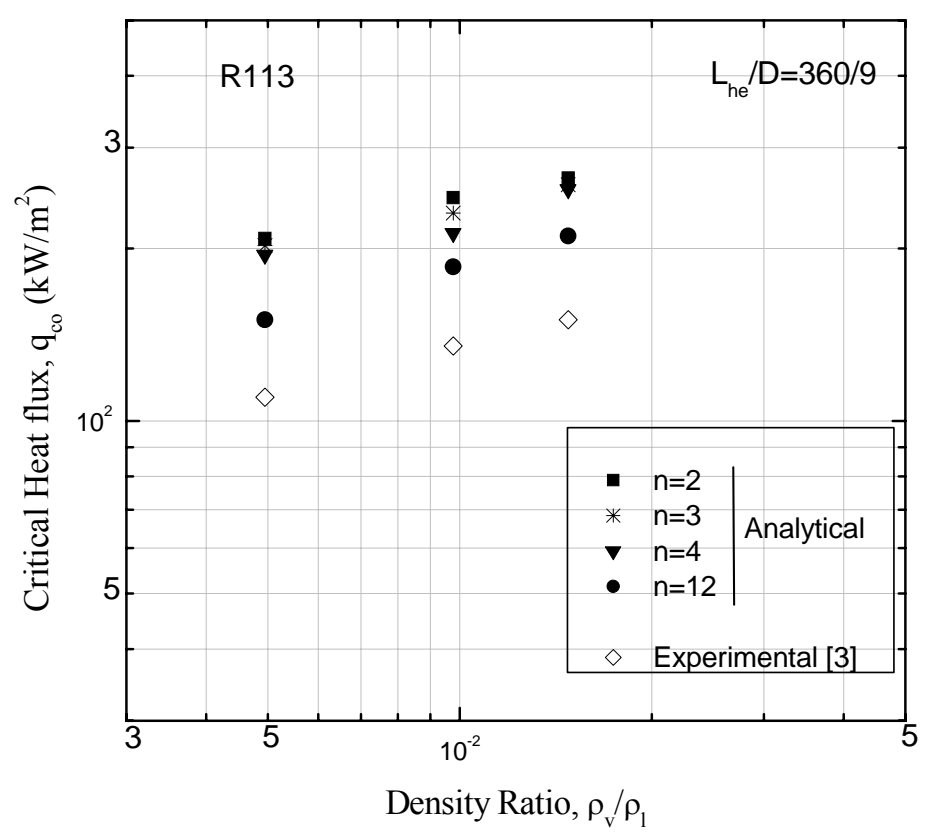

Figure 9. Effect of profile index ' $n$ ' on CHF at different pressure

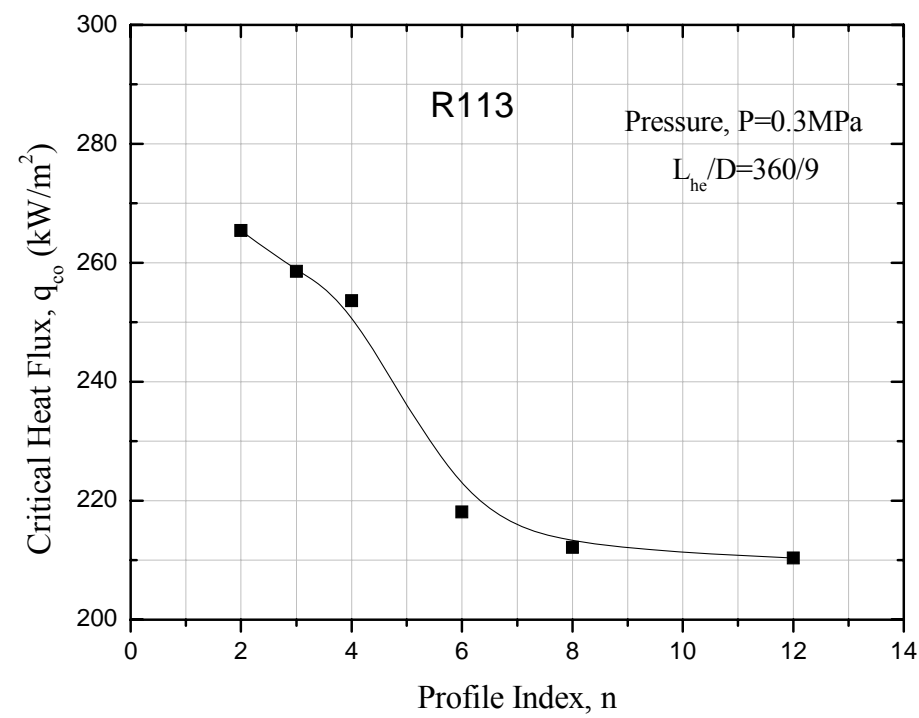

Figure 10. Effect of profile index, $\mathrm{n}$ on $\mathrm{CHF}$

\subsection{Performance of the model}

To test the basic performance of the present analytical model, the CHF data of R113, R12 and Water of this analysis have been compared with the experimental data that were measured by Monde and Yamaji (1990) at the same geometry and thermalhydraulic conditions. The comparison was done with the help of Kutateladze correlation (17). Figures 11, 12 and 13 show the comparison of reciprocal of Kutateladze number for experimental model with that of the present analytical model. Though these figures for R113, R12 and water indicate that the present model has the tendency to over-and under-predict the experimental CHF values, the analytical CHF values agree with the experimental CHF within $\pm 50 \%$. Also the ratios between experimental and analytical critical heat fluxes, $\mathrm{q}_{\mathrm{co}}$ (experimental)/ $\mathrm{q}_{\mathrm{co}}$ (analytical) are potted against $\mathrm{L}_{\mathrm{he}} / \mathrm{D}$ in Figure 14 . It shows that the present model predicts the CHF well within $\pm 50 \%$ for $\mathrm{L}_{\mathrm{he}} / \mathrm{D}>20$ but the significant scattering is seen in case of small $\mathrm{L}_{\mathrm{he}} / \mathrm{D}$. For shorter $\mathrm{L}_{\mathrm{he}} / \mathrm{D}$, the CHF characteristics are presumably similar to that of pool boiling giving its higher values as observed for both the 
present and existing experimental study. However, the analytical values are much higher than the experimental values which may be due to the choice of profile index as $\mathrm{n}=2$. Higher profile index can be used for better performance.

In addition, acceleration of the vapor core during vaporization process very often produces entrainment of the liquid droplet. This effect, together with direct vaporization of the film, tends to reduce the film thickness quickly than with no entrainment resulting in the decrease in CHF. But the present model did not consider entrainment and thus over-predicts the CHF.

Phase-change systems are almost always subjected to instability associated with the liquid-vapor interface. This kind of instability of interface has strong impact on heat and mass transfer during phase change process, which is not considered in the present model. This may also be one of the reasons of over-predicting CHF by this model.

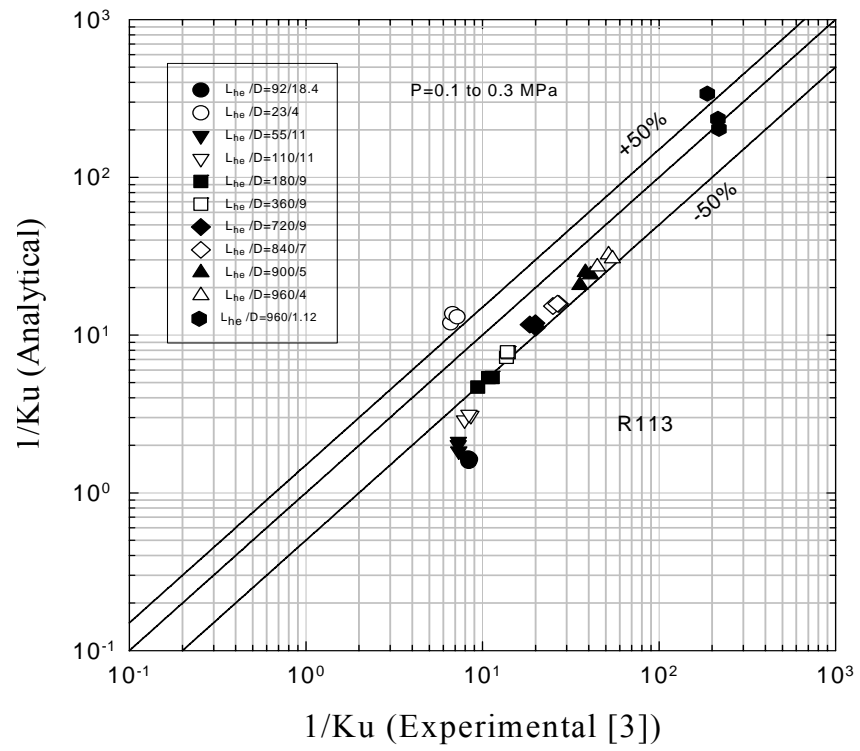

Figure 11. Comparison between analytical and experimental CHF for R113

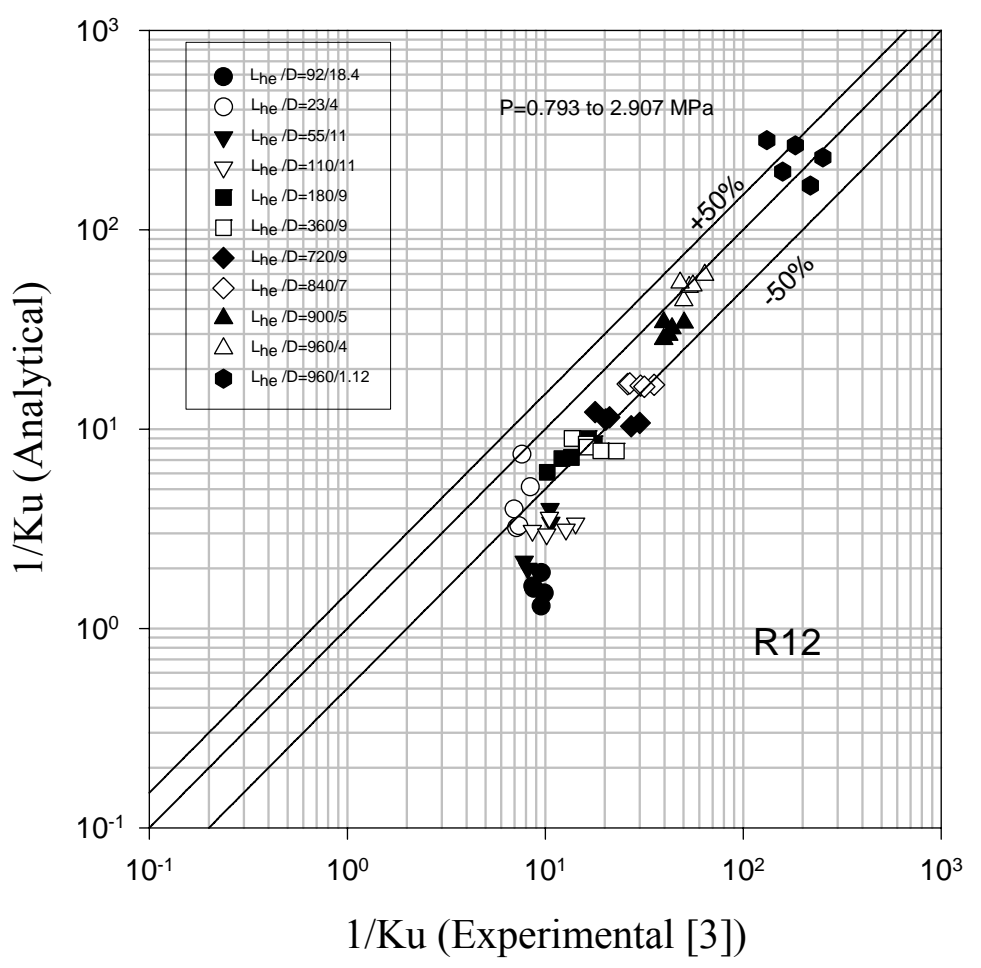

Figure 12. Comparison between analytical and experimental CHF for R12 


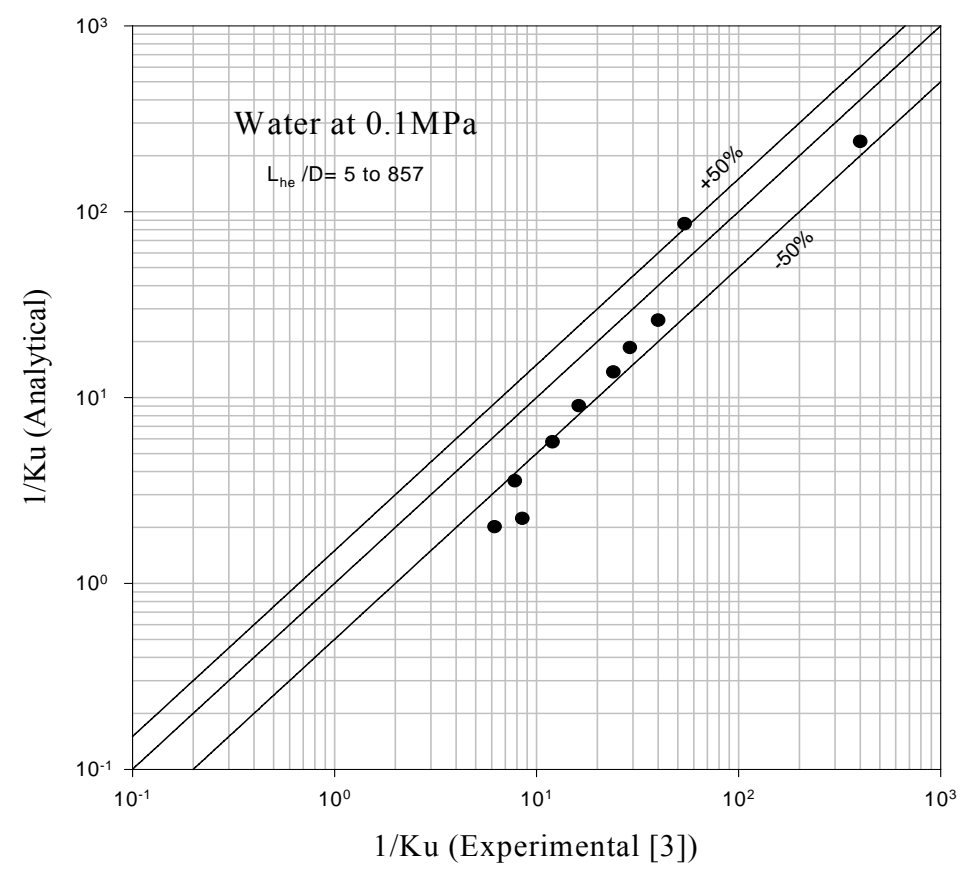

Figure 13. Comparison between analytical and experimental CHF for water

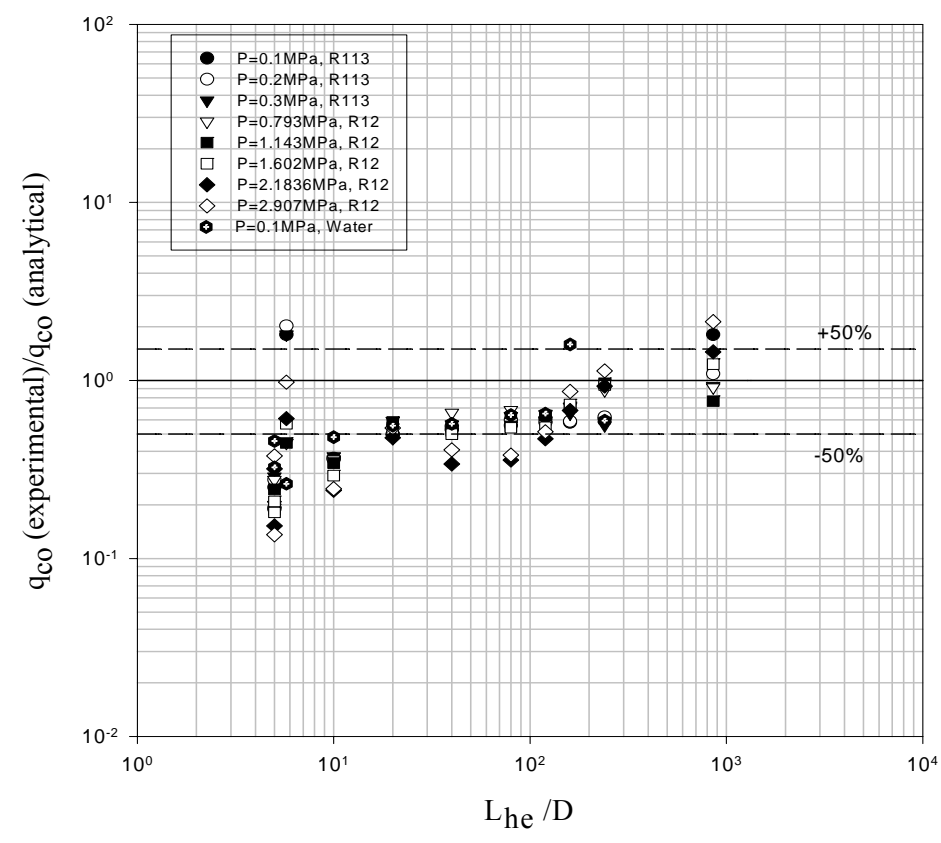

Figure 14. Dependence of the present model on $\mathrm{L}_{\mathrm{he}} / \mathrm{D}$

\section{Conclusions}

1. This model considers mass, momentum, and energy balances for the two-phase flow in a vertical tube submerged in a saturated liquid, where the liquid-vapor interface is a paraboloid formed by $\mathrm{z} / \mathrm{L}=\left(\mathrm{r} / \mathrm{r}_{\mathrm{o}}\right)^{\mathrm{n}}$. The CHF assume to take place at the exit of the heated tube when the void fraction is unity and the mass flux, $G$ is maximum.

2. The predicted CHF values show similar characteristics as shown in available experimental studies.

3. The liquid-vapor interface profile index, ' $n$ ' has significant effect on CHF upto value of 8 , then further increase of its value shows very little effect on CHF.

4. The variations of the CHF with the $\mathrm{L}_{\mathrm{he}} / \mathrm{D}$ are more significant for $\mathrm{L}_{\mathrm{he}} / \mathrm{D}<50$. 
5. The predicted CHF agreed well with the experimental data within $\pm 50 \%$ for $\mathrm{L}_{\mathrm{he}} / \mathrm{D}>20$.

6. The mass transfer due to entrainment and deposition of the liquid droplets between the liquid and vapor phases is not considered in this model which could be incorporated for the improvement of this model.

7. Instability associated with the liquid-vapor interface can also be taken into account in this model rather than assuming the interface as a smooth curve because instability of the interface has strong impact on heat and mass transfer during phase change process.

\section{Nomenclature}

A Cross sectional area of the tube $\left[\mathrm{m}^{2}\right]$

$\mathrm{A}_{1} \quad$ Cross sectional area of the liquid column $\left[\mathrm{m}^{2}\right]$

$\mathrm{A}_{\mathrm{v}} \quad$ Cross sectional area of the vapor column $\left[\mathrm{m}^{2}\right]$

$\mathrm{C}_{\mathrm{fw}} \quad$ Wall friction factor

CS Control surface

$\mathrm{CV}$ Control volume

D Tube diameter $[\mathrm{m}]$

G Mass flux $\left[\mathrm{kg} / \mathrm{m}^{2} \mathrm{~s}\right]$

g Gravitational acceleration $\left[\mathrm{m} / \mathrm{s}^{2}\right]$

$\mathrm{H}_{\mathrm{gg}} \quad$ Latent heat of evaporation $[\mathrm{kJ} / \mathrm{kg}]$

$\mathrm{j}_{1} \quad$ Superficial liquid velocity $[\mathrm{m} / \mathrm{s}]$

$\mathrm{Ku} \quad$ Kutateladze number $=\frac{\mathrm{q}_{\mathrm{co}} / \rho_{\mathrm{v}} \mathrm{H}_{\mathrm{lg}}}{\sqrt[4]{\sigma \mathrm{g}\left(\rho_{1}-\rho_{\mathrm{v}}\right) / \rho_{\mathrm{v}}^{2}}}[-]$

$\mathrm{L} \quad$ Liquid-vapor interface profile length [m]

$\mathrm{L}_{\mathrm{he}} \quad$ Tube heating length [m]

$\mathrm{L}^{+} \quad \mathrm{L}_{\mathrm{he}} / \mathrm{L}[-]$

n Profile index

$\mathrm{P} \quad$ System pressure [MPa]

$\mathrm{P}_{\mathrm{c}} \quad$ Critical pressure [MPa]

$\mathrm{P}_{\mathrm{r}} \quad$ Reduced pressure $\left[=\mathrm{P} / \mathrm{P}_{\mathrm{c}}\right]$

q" Heat flux supplied [kW/ $\left.\mathrm{m}^{2}\right]$

$\mathrm{q}_{\mathrm{co}} \quad$ CHF for saturated boiling $\left[\mathrm{kW} / \mathrm{m}^{2}\right]$

$\mathrm{Re}_{1} \quad$ Reynolds number for liquid

$\mathrm{r} \quad$ Radial coordinate [m]

$\mathrm{r}_{\mathrm{o}} \quad$ Radius of the tube $[\mathrm{m}]$

$\mathrm{u} \quad$ Fluid velocity $[\mathrm{m} / \mathrm{s}]$

$\mathrm{z} \quad$ Vertical coordinate along the tube [m]

$\mathrm{z}^{+} \quad \mathrm{z} / \mathrm{L}[-]$

\section{Greek Symbols}

$\alpha \quad$ Void fraction $\left[=\mathrm{A}_{\mathrm{v}} / \mathrm{A}\right]$ or $\left[=(\mathrm{z} / \mathrm{L})^{2 / \mathrm{n}}\right]$

$\rho \quad$ Fluid Density $\left[\mathrm{kg} / \mathrm{m}^{3}\right]$

$\sigma \quad$ Surface tension at vapor-liquid interface $[\mathrm{N} / \mathrm{m}]$

$\tau_{\mathrm{i}} \quad$ Interfacial shear stress $\left[\mathrm{N} / \mathrm{m}^{2}\right]$

$\tau \quad$ Shear stress $\left[\mathrm{N} / \mathrm{m}^{2}\right]$

$\mu \quad$ Viscosity [Pa.s]

\section{Subscripts}

co Critical condition in saturated boiling

i Liquid-vapor interface

1 Liquid

$\lg \quad$ Liquid-vapor phase change

max Maximum

v Vapor

w Wall 


\section{References}

Afroz H. M. M., 2004. An analytical study of critical heat flux in natural convective boiling in a vertical tube. M.Sc. (ME) Thesis, Bangladesh University of Engineering \& Technology (BUET), pp. 21-31.

Govan A. M., Hewitt G. F., Owen D. G., and Bott T. R., 1988. An improved CHF modeling code. Proceedings of $2^{\text {nd }}$ U.K. Conf. Heat Transfer, Institute of Mechanical Engineers, London, Vol. 1, pp. 33-48.

Haramura Y., and Katto Y., 1983. A new hydrodynamic model of critical heat flux, applicable widely to both pool and forced convection boiling on submerged bodies in saturated liquids. Intl. J. Heat and Mass Transfer Vol. 26, pp.379-399.

Katto Y., 1978. Generalized correlation for Critical Heat Flux of natural convection boiling in confined channels. Transaction of JSME (in Japanese), Vol. 44, pp. 3908-3911.

Katto Y. and Kurosaka T., 1979. Critical Heat Flux of natural convection boiling in vertical annular channels. Proceedings of the $15^{\text {th }}$ National Heat Transfer Symposium of Japan, pp. 280-282.

Katto Y., and Yokoya, 1970. Principal mechanism of boiling Crisis in pool boiling. Intl. J. Heat and Mass Transfer Vol.11, pp. 993-1002.

Monde M. and Yamaji K., 1990. Critical Heat Flux during natural convective boiling in vertical uniformly heated tubes submerged in saturated liquid, Proceedings of $9^{\text {th }}$ Heat Transfer Conference, Jerusalem, Israel, pp. 111-116.

Monde M., Mihara S., and Inoue T., 1993. An analytical study of the Critical Heat Flux of a Two-phase thermosyphon. Heat Transfer-Japanese Research, Vol. 22, No. 6, pp. 611-623.

Monde M., 1996. Analytical study of critical heat flux in two-phase thermosyphon: relationship between maximum falling liquid rate and critical heat flux. Trans. ASME, J, Heat Transfer, Vol. 118, pp.422-428.

Okawa T., Kotani A., Katako I., and Naito M., 2003. Prediction of Critical Heat Flux in annular flow using a film flow model, Journal of Nuclear Science and Technology, Vol. 40, N0. 6, pp. 388-396.

Stephan K., 1987. Heat transfer in condensation and boiling. Springer-Verlag, pp.160-161.

Wallis G. B., 1969. One Dimensional Two-Phase Flow. McGraw- Hill, New York, p. 339.

Whalley P. B., Hutchinson P., and Hewitt G. F., 1974a. The calculation of critical heat flux in forced convective boiling. Proceedings of $5^{\text {th }}$ Int. Heat Transfer Conf., Tokyo, Paper B6. 11.

Whalley P. B., 1976. The calculation of dryout in rod bundle. Br. Report AERE-R8319.

Whalley P. B., Hutchinson P., and Hewitt G. F., 1974b. Prediction of annular flow parameters for transient flows and for complex geometries. Br. Report AERE-M2661.

\section{Biographical notes}

Dr. Hasan mohammad Mostofa Afroz is an Associate Professor in the Department of Mechanical Engineering, Dhaka University of Engineering \& Technology (DUET), Bangladesh. He is doing research in the field of thermal engineering and fluid flow. He received his Ph.D degree on thermal engineering from Saga University, Japan.

Dr. Md. Ashraful Islam is a professor in the Department of Mechanical Engineering, Bangladesh University of Engineering \& Technology (BUET), Bangladesh. He did his Ph.D from Saga University, Japan. His field of research is heat transfer. He has many years of experience in teaching and research. He has published many papers in referred international journals and presented many research articles in national and international conferences.

Received November 2010

Accepted December 2010

Final acceptance in revised form December 2010

\section{Appendix}

$F_{P}, F_{G}, F_{w}, \& F_{M}$ can be simplified as follows:

\section{EVALUATION OF $F_{P}$}

$F_{P}=\left[\int_{\text {CSI }} P d A+\int_{\text {CSII }} P d A\right]=\int_{\text {aed }} P_{1} d A-\int_{a d} P_{v} d A-\int_{\text {aed }} P_{v} d A+\int_{b c} P_{l} d A=\left[\int_{\text {aed }} P_{l} d A-\int_{\text {aed }} P_{v} d A\right]+\left[\int_{b c} P_{l} d A-\int_{a d} P_{v} d A\right]$

Surface tension force

Buoyancy force

$\therefore \mathrm{F}_{\mathrm{P}}=2 \pi \mathrm{r}_{\mathrm{o}} \sigma+\rho_{\mathrm{l}} \mathrm{g} \pi \mathrm{r}_{\mathrm{o}}^{2} \mathrm{~L}$ 


\section{EVALUATION OF F $_{G}$}

$$
\begin{aligned}
& \mathrm{F}_{\mathrm{G}}=\mathrm{g}\left[\int_{\mathrm{CVI}} \rho_{\mathrm{v}} \mathrm{dV}+\int_{\mathrm{CVII}} \rho_{\mathrm{l}} \mathrm{dV}\right] \quad=\mathrm{g}\left[\int_{0}^{\mathrm{L}} \rho_{\mathrm{v}} \mathrm{A}_{\mathrm{v}} \mathrm{dz}+\int_{\mathrm{o}}^{\mathrm{L}} \rho_{\mathrm{l}} \mathrm{A}_{1} \mathrm{dz}\right] \\
& =\operatorname{Ag}\left[\int_{0}^{\mathrm{L}} \rho_{\mathrm{v}} \frac{\mathrm{A}_{\mathrm{v}}}{\mathrm{A}} \mathrm{dz}+\int_{0}^{\mathrm{L}} \rho_{1} \frac{\mathrm{A}_{1}}{\mathrm{~A}} \mathrm{dz}\right]=\pi \mathrm{r}_{0}^{2} \mathrm{~g}\left[\int_{0}^{\mathrm{L}} \rho_{\mathrm{v}} \alpha \mathrm{dz}+\int_{0}^{\mathrm{L}} \rho_{1}(1-\alpha) \mathrm{dz}\right]=\pi \mathrm{r}_{0}^{2} \mathrm{~g}\left[\left(\rho_{\mathrm{v}}-\rho_{1}\right) \int_{0}^{\mathrm{L}} \alpha \mathrm{dz}+\rho_{1} \int_{0}^{\mathrm{L}} \mathrm{dz}\right] \\
& =\pi r_{0}^{2} g\left[\left(\rho_{v}-\rho_{1}\right) \int_{0}^{L}\left(\frac{z}{L}\right)^{\frac{2}{n}} d z+\rho_{1} \int_{0}^{L} d z\right] \\
& \therefore \mathrm{F}_{\mathrm{G}}=\pi \mathrm{r}_{\mathrm{o}}^{2} \mathrm{gL}\left[\left(\rho_{\mathrm{v}}-\rho_{1}\right) \frac{\mathrm{n}}{\mathrm{n}+2}+\rho_{1}\right]
\end{aligned}
$$

\section{EVALUATION OF $\mathbf{F}_{M}$}

$\mathrm{F}_{\mathrm{M}}=\int_{\text {CSI }}(\mathrm{G} . \mathrm{u})_{\text {out }} \mathrm{dA}-\int_{\text {CSII }}(\mathrm{G} . \mathrm{u})_{\text {in }} \mathrm{dA}$

Here, $\int_{\text {CSI }}(G . u)_{\text {out }} d A=\int_{0}^{r_{o}} \rho_{v} u_{v}^{2} \cdot 2 \pi r . d r, \quad=\int_{0}^{r_{0}} 2 \pi r \rho_{v} u_{\max }^{2}\left(1-\frac{r}{r_{0}}\right)^{\frac{2}{7}} d r$, as $\left.\quad \mathrm{u}_{\mathrm{v}}(\mathrm{r})=\mathrm{u}_{\max }\left(1-\frac{\mathrm{r}}{\mathrm{r}_{\mathrm{o}}}\right)^{\frac{1}{7}}\right]$

$\therefore \int_{\text {CSI }}(\text { G.u })_{\text {out }} \mathrm{dA}=2 \pi \rho_{\mathrm{v}} \mathrm{u}_{\max }^{2} \mathrm{I}_{1}, \quad$ Let, $\mathrm{I}_{1}=\int_{\mathrm{o}}^{\mathrm{r}_{\mathrm{o}}} \mathrm{r}\left(1-\frac{\mathrm{r}}{\mathrm{r}_{\mathrm{o}}}\right)^{\frac{2}{7}} \mathrm{dr}$

Substituting $1-\frac{r}{r_{o}}=z$, we get $I_{1}=\frac{49}{144} r_{o}^{2}$

$u_{\text {mean }}=\frac{\text { Total volume per unit time pas sing through the sec tion }}{\text { Total area of cross sec tion }}$ and $u_{\text {mean }}=\frac{1}{\pi r_{o}^{2}} \int_{0}^{r_{o}} u_{v} d_{A_{v}}=\frac{1}{\pi r_{o}^{2}} \int_{0}^{r_{o}} u_{\max } 2 \pi r\left(1-\frac{r}{r_{0}}\right)^{\frac{1}{7}} d r$

Considering $1-\frac{r}{r_{0}}=z$, we get

$\therefore \mathrm{u}_{\text {mean }}=2 \mathrm{u}_{\max } \int_{\mathrm{o}}^{1}(1-\mathrm{z}) \mathrm{z}^{\frac{1}{7}} \mathrm{dz} \ldots \mathrm{u}_{\text {max }}^{2}=\frac{60^{2}}{49^{2}} \mathrm{u}_{\text {mean }}^{2}$

$\mathrm{u}_{\max }^{2}=\frac{60^{2}}{49^{2}} \frac{\mathrm{G}^{2}}{\rho_{\mathrm{v}}^{2}}$,

as $\left[\mathrm{G}=\rho_{\mathrm{v}} \mathrm{u}_{\text {mean }}\right]$

Using the value of $I_{1}$ and $u_{\max }$ we get,

$\int_{\text {CSI }}(G . u)_{\text {out }} \mathrm{dA}=\frac{50}{49} \pi \mathrm{r}_{\mathrm{o}}^{2} \frac{\mathrm{G}^{2}}{\rho_{\mathrm{v}}} . \Rightarrow \int_{\text {CSI }}(\mathrm{G} . \mathrm{u})_{\text {out }} \mathrm{dA}=\mathrm{k}_{\mathrm{v}} \mathrm{r}_{\mathrm{o}}^{2} \frac{\mathrm{G}^{2}}{\rho_{\mathrm{v}}}, \quad$ Where, $\mathrm{k}_{\mathrm{v}}=\frac{50}{49} \pi$

Again, $\int_{\text {CSII }}(\mathrm{G} . \mathrm{u})_{\text {in }} \mathrm{dA}$ can be analyzed by the following way,

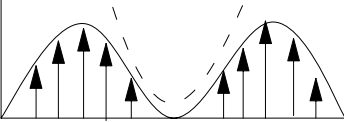

Figure 15. Velocity profile of liquid at inlet 
Let the inlet velocity profile for liquid is

$\mathrm{u}_{1}(\mathrm{r})=\mathrm{A}+\mathrm{Br}+\mathrm{Cr}^{2}+\mathrm{Dr}^{3}$

With boundary conditions,

$\begin{array}{lll}\text { (i) } r=0, \quad u=0 ; & \text { (ii) } r=0, \quad \frac{\partial u}{\partial r}=0 ; \quad \text { (iii) } r=r_{0}, \quad u=0\end{array}$

Applying boundary conditions in (A-1), we get,

$\mathrm{u}_{1}(\mathrm{r})=-\mathrm{Dr}_{\mathrm{o}} \mathrm{r}^{2}+\mathrm{Dr}^{3}$

Again if $\bar{U}$ be the mean velocity at the inlet, then,

$$
\begin{aligned}
& \pi \mathrm{r}_{0}^{2} \overline{\mathrm{U}}=\int_{\mathrm{o}}^{\mathrm{r}_{\mathrm{o}}} 2 \pi \mathrm{r} \cdot \mathrm{u}(\mathrm{r}) \cdot \mathrm{dr}=2 \pi \mathrm{D} \int_{\mathrm{o}}^{\mathrm{r}_{\mathrm{o}}}\left(\mathrm{r}^{4}-\mathrm{r}_{\mathrm{o}} \mathrm{r}^{3}\right) \mathrm{dr} . \therefore \mathrm{D}=\frac{-10 \overline{\mathrm{U}}}{\mathrm{r}_{\mathrm{o}}^{3}} \text { and } \therefore \mathrm{u}_{1}(\mathrm{r})=10 \overline{\mathrm{U}} \cdot\left(\frac{\mathrm{r}}{\mathrm{r}_{\mathrm{o}}}\right)^{2} \cdot\left(1-\frac{\mathrm{r}}{\mathrm{r}_{\mathrm{o}}}\right) \\
& \therefore \int_{\text {CSII }}(\mathrm{Gu})_{\text {in }} \mathrm{dA}=\int_{\mathrm{o}}^{\mathrm{r}_{\mathrm{o}}} 2 \pi \cdot \rho_{1} \mathrm{u}_{1}^{2} \mathrm{r} \cdot \mathrm{dr} \quad \text { as } \mathrm{G}_{1}=\rho_{1} \mathrm{u}_{1} \\
& =2 \pi \rho_{1} \int_{\mathrm{o}}^{\mathrm{r}_{0}}\left[10 \overline{\mathrm{U}} \cdot\left(\frac{\mathrm{r}}{\mathrm{r}_{\mathrm{o}}}\right)^{2} \cdot\left(1-\frac{\mathrm{r}}{\mathrm{r}_{\mathrm{o}}}\right)\right]^{2} \cdot \mathrm{rdr} \quad \text { as } \quad \overline{\mathrm{U}}=\frac{\mathrm{G}}{\rho_{\mathrm{l}}} \\
& =\frac{25}{21} \cdot\left(\pi \mathrm{r}_{\mathrm{o}}^{2}\right) \cdot \frac{\mathrm{G}^{2}}{\rho_{1}} \\
& \int_{\text {CSII }}(\mathrm{G} \cdot \mathrm{u})_{\text {in }} \mathrm{dA}=\mathrm{k}_{1} \frac{\mathrm{r}^{2} \mathrm{G}^{2}}{\rho_{1}}, \quad \text { Here, } \mathrm{k}_{1}=\frac{25}{21} \cdot \pi . \therefore \mathrm{F}_{\mathrm{M}}=\left(\frac{\mathrm{k}_{\mathrm{v}}}{\rho_{\mathrm{v}}}-\frac{\mathrm{k}_{1}}{\rho_{1}}\right) \cdot \mathrm{r}_{\mathrm{o}}^{2} \cdot \mathrm{G}^{2}
\end{aligned}
$$

\section{EVALUATION OF $\mathbf{F}_{\mathrm{W}}$}

$$
\begin{aligned}
& \mathrm{F}_{\mathrm{w}}=\int_{0}^{\mathrm{L}} 2 \pi \mathrm{r}_{0} \tau_{\mathrm{w}} \mathrm{dz} \\
& \tau_{\mathrm{w}}=\frac{1}{2} \mathrm{C}_{\mathrm{fw}} \rho_{1} \mathrm{u}_{1}^{2}=\frac{1}{2} \mathrm{C}_{\mathrm{fw}} \rho_{1} \frac{\mathrm{j}_{1}^{2}}{(1-\alpha)^{2}}, \quad \text { as } \mathrm{j}_{1}=(1-\alpha) \mathrm{u}_{1} \\
& \therefore \mathrm{F}_{\mathrm{w}}=\pi \mathrm{r}_{0} \rho_{1} \int_{0}^{\mathrm{L}} \mathrm{C}_{\mathrm{fw}} \frac{\mathrm{j}_{1}^{2}}{(1-\alpha)^{2}} \mathrm{dz}
\end{aligned}
$$

$\mathrm{C}_{\mathrm{fw}}$ can be obtained by the equations (10)-(12).

The variation of the superficial liquid velocity, $\mathrm{j}_{1}$ along the length of the tube can be analyzed as follows-

For $\mathbf{L}>\mathbf{L}_{\mathbf{h e}}$ or $\left[\mathbf{L}^{+}=\frac{\mathbf{L}_{\mathbf{h e}}}{\mathbf{L}}<\mathbf{1}\right]$

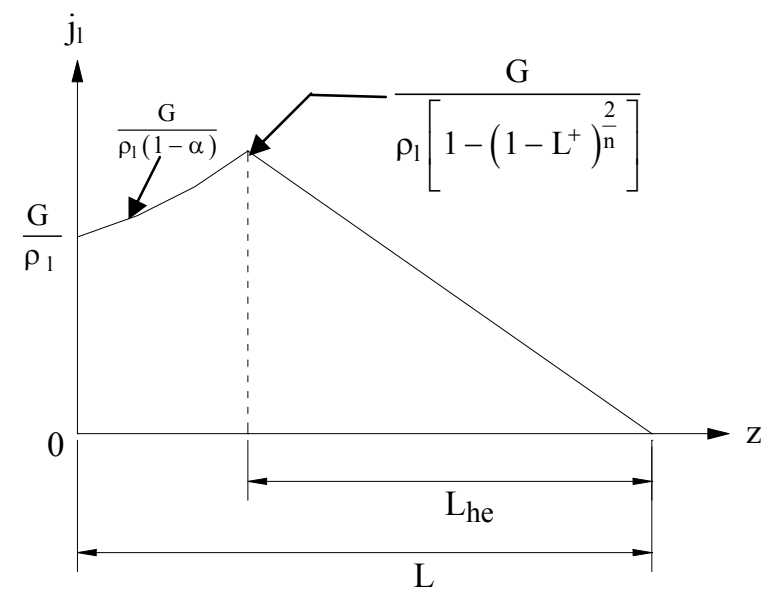

Figure 16. Liquid velocity variation for $\mathrm{L}>\mathrm{L}_{\mathrm{he}}$ 
For $z=0$ to $\left(L-L_{h e}\right)$ liquid enters into the main flow from the side because tube wall is not exist there, so that increasing $j_{1}$ is seen in this region as $j_{1}=\frac{G}{\rho_{1}(1-\alpha)}$.

$\therefore \mathrm{j}_{1}=\frac{\mathrm{G}}{\rho_{1}\left(1-\mathrm{z}^{+\frac{2}{\mathrm{n}}}\right)}, \quad 0 \leq \mathrm{z}^{+} \leq 1-\mathrm{L}^{+}$

And, $j_{1}=\frac{G\left(1-z^{+}\right)}{\rho_{1}\left[1-\left(1-L^{+}\right)^{\frac{2}{n}}\right] \cdot L^{+}}, \quad 1-L^{+} \leq z^{+} \leq 1$

$\therefore \operatorname{Re}_{\mathrm{f}}=\frac{\rho_{1} \cdot \mathrm{j}_{1} \cdot \mathrm{D}}{\mu_{1}}=\frac{\text { G.D }}{\mu_{1}\left[1-\mathrm{z}^{+\frac{2}{\mathrm{n}}}\right]}, \quad 0 \leq \mathrm{z}^{+} \leq 1-\mathrm{L}^{+}$

And $\operatorname{Re}_{\mathrm{f}}=\frac{\text { G.D. }\left(1-\mathrm{z}^{+}\right)}{\mu_{1}\left[1-\left(1-\mathrm{L}^{+}\right)^{\frac{2}{n}}\right] \cdot \mathrm{L}^{+}}, \quad \quad 1-\mathrm{L}^{+} \leq \mathrm{z}^{+} \leq 1$

For $\mathbf{L}=\mathbf{L}_{\mathrm{he}}$ ie. $\mathbf{L}^{+}=\mathbf{1}$

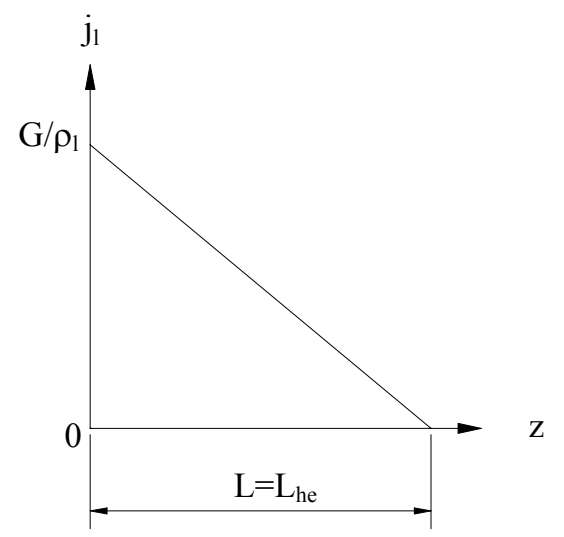

Figure 17. Liquid velocity variation for $\mathrm{L}=\mathrm{L}_{\mathrm{he}}$

Here at $\mathrm{z}=0, \mathrm{j}_{1}=\mathrm{G} / \rho_{\mathrm{l}}$ as $\alpha=0$ (flow is in liquid phase only)

$\therefore \mathrm{j}_{1}=\frac{\mathrm{G}\left(1-\mathrm{z}^{+}\right)}{\rho_{1}}$

for $0 \leq \mathrm{z}^{+} \leq 1$

$\operatorname{Re}_{\mathrm{f}}=\frac{\text { G.D. }\left(1-\mathrm{z}^{+}\right)}{\mu_{1}}$

for $0 \leq \mathrm{z}^{+} \leq 1$ 
For $\mathbf{L}<\mathbf{L}_{\text {he, }}$ ie. $\mathbf{L}^{+}>\mathbf{1}$

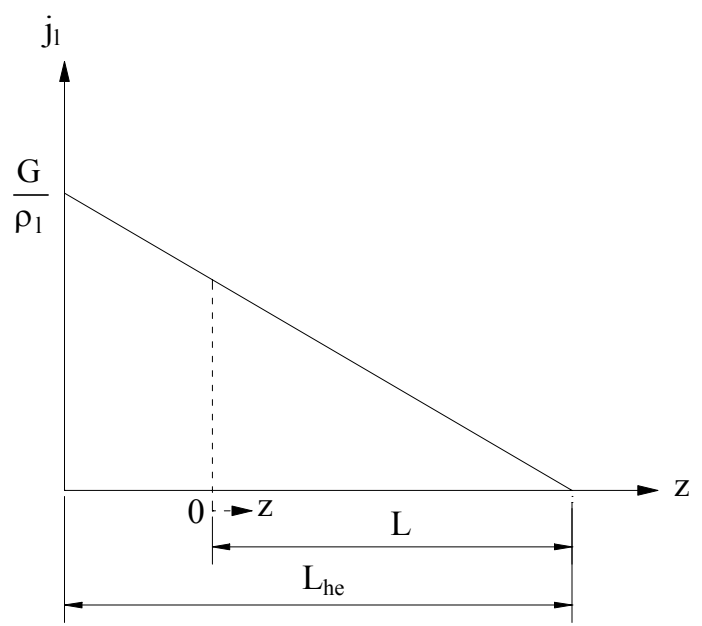

Figure 18. Liquid velocity variation for $\mathrm{L}<\mathrm{L}_{\mathrm{he}}$

For $\mathrm{z}=-\left(\mathrm{L}_{\mathrm{he}}-\mathrm{L}\right)$ to $0, \mathrm{j}_{1}$ decreases due to wall friction only because in this region $\alpha=0$ and $\mathrm{j}_{1}=\mathrm{G} / \rho_{1} \mathrm{~L}^{+}$at $\mathrm{z}=0$.

$$
\begin{aligned}
\therefore j_{1}=\frac{G\left(1-z^{+}\right)}{\rho_{1} L^{+}} & \text {for } 0 \leq z^{+} \leq 1 \\
\operatorname{Re}_{f}=\frac{G \cdot D \cdot\left(1-z^{+}\right)}{\mu_{1} L^{+}} & \text {for } 0 \leq z^{+} \leq 1
\end{aligned}
$$

Now using the above relations of $j_{1}$ and $\mathrm{Re}_{\mathrm{f}}$ and the equation (A-2) we can get the expression of frictional force for various conditions as follows-

\section{For $\mathbf{L}>\mathbf{L}_{h e}$ or $\mathbf{L}^{+}<\mathbf{1}$}

$\mathrm{F}_{\mathrm{w}}=\pi \mathrm{r}_{0} \mathrm{~L} \rho_{1} \int_{0}^{1} \mathrm{C}_{\mathrm{fw}} \frac{\mathrm{j}_{1}^{2}}{\left[1-\left(\mathrm{z}^{+}\right)^{2 / \mathrm{n}}\right]^{2}} \mathrm{dz}$

Using Eq. A-2 and Eqs. (10)- (12), we get,

$$
\begin{aligned}
& \mathrm{F}_{\mathrm{w}}=\pi_{0} \mathrm{~L}_{\mathrm{l}}\left[\int_{0}^{1-\mathrm{L}^{+}} \mathrm{C}_{\mathrm{fw}} \frac{\mathrm{G}^{2}}{\rho_{\mathrm{l}}^{2}\left\{1-\left(\mathrm{z}^{+}\right)^{2 / \mathrm{n}}\right\}^{2} \cdot\left\{1-\left(\mathrm{z}^{+}\right)^{2 / n}\right\}^{2}} \mathrm{dz} \mathrm{z}^{+}+\int_{1-\mathrm{L}^{+}}^{1} \mathrm{C}_{\mathrm{fw}} \frac{\mathrm{G}^{2}\left(1-\mathrm{z}^{+}\right)^{2}}{\rho_{\mathrm{l}}^{2}\left\{1-\left(1-\mathrm{L}^{+}\right)^{2 / \mathrm{n}}\right\}^{2} \mathrm{~L}^{+2} \cdot\left\{1-\left(\mathrm{z}^{+}\right)^{2 / \mathrm{n}}\right\}^{2}} \mathrm{dz}\right] \\
& \Rightarrow \mathrm{F}_{\mathrm{w}}=\frac{\pi \mathrm{r}_{0} \mathrm{G}^{2} \mathrm{~L}}{\rho_{1}}\left[\int_{0}^{1-\mathrm{L}^{+}} \frac{\mathrm{C}_{\mathrm{fw}}}{\left\{1-\left(\mathrm{z}^{+}\right)^{2 / \mathrm{n}}\right\}^{4}} \mathrm{dz}^{+}+\int_{1-\mathrm{L}^{+}}^{1} \frac{\mathrm{C}_{\mathrm{fw}}\left(1-\mathrm{z}^{+}\right)^{2}}{\left\{1-\left(1-\mathrm{L}^{+}\right)^{2 / n}\right\}^{2} \mathrm{~L}^{+2} \cdot\left\{1-\left(\mathrm{z}^{+}\right)^{2 / \mathrm{n}}\right\}^{2}} \mathrm{dz} \mathrm{z}^{+}\right] \\
& \Rightarrow \mathrm{F}_{\mathrm{w}}=\frac{\pi \mathrm{r}_{0} \mathrm{G}^{2} \mathrm{~L}}{\rho_{\mathrm{l}}} \mathrm{I}
\end{aligned}
$$

Where,

$$
I=\left[\int_{0}^{1-L^{+}} \frac{C_{f w}}{\left\{1-\left(z^{+}\right)^{2 / n}\right\}^{4}} d z^{+}+\int_{1-L^{+}}^{1} \frac{C_{f w}\left(1-z^{+}\right)^{2}}{\left\{1-\left(1-L^{+}\right)^{2 / n}\right\}^{2} L^{+2} \cdot\left\{1-\left(z^{+}\right)^{2 / n}\right\}^{2}} d z^{+}\right]
$$

Let $\quad \mathrm{I}=\mathrm{I}_{1}+\mathrm{I}_{2}$ 
Here, $I_{1}=\int_{0}^{1-\mathrm{L}^{+}} \frac{\mathrm{C}_{\mathrm{fw}}}{\left\{1-\left(\mathrm{z}^{+}\right)^{2 / \mathrm{n}}\right\}^{4}} \mathrm{dz}^{+}$and $\mathrm{I}_{2}=\int_{1-\mathrm{L}^{+}}^{1} \frac{\mathrm{C}_{\mathrm{fw}}\left(1-\mathrm{z}^{+}\right)^{2}}{\left\{1-\left(1-\mathrm{L}^{+}\right)^{2 / \mathrm{n}}\right\}^{2} \mathrm{~L}^{+2} \cdot\left\{1-\left(\mathrm{z}^{+}\right)^{2 / \mathrm{n}}\right\}^{2}} d \mathrm{z}^{+}$

The Leibniz Integral rule

$\frac{\partial}{\partial z} \int_{a(z)}^{b(z)} f(x, z) d x=\int_{a(z)}^{b(z)} \frac{\partial f}{\partial z} d x+f(b(z), z) \frac{\partial b}{\partial z}-f(a(z), z) \frac{\partial a}{\partial z}$

$\frac{\partial \mathrm{I}_{1}}{\partial \mathrm{L}}=\int_{0}^{1-\mathrm{L}^{+}} \frac{\partial \mathrm{C}_{\mathrm{fw}}}{\partial \mathrm{L}} \frac{\mathrm{dz}^{+}}{\left\{1-\left(\mathrm{z}^{+}\right)^{2 / \mathrm{n}}\right\}^{4}}+\frac{\mathrm{C}_{\mathrm{fw}}}{\left\{1-\left(1-\mathrm{L}^{+}\right)^{2 / \mathrm{n}}\right\}^{4}} \frac{\partial\left(1-\mathrm{L}^{+}\right)}{\partial \mathrm{L}}$

Let $\mathrm{x}=\left[1-\left(1-\mathrm{L}^{+}\right)^{2 / \mathrm{n}}\right]^{4} . \therefore \frac{\mathrm{dx}}{\mathrm{dL}}=\frac{-2}{\mathrm{n}}\left(1-\mathrm{L}^{+}\right)^{\frac{2}{n}-1} \frac{\mathrm{L}^{+2}}{\mathrm{~L}_{\mathrm{he}}}$

Now, $\frac{\partial \mathrm{C}_{\mathrm{fw}}}{\partial \mathrm{L}}=\frac{\partial \mathrm{C}_{\mathrm{fw}}}{\partial \mathrm{Re}_{\mathrm{f}}} \cdot \frac{\partial \mathrm{Re}_{\mathrm{f}}}{\partial \mathrm{L}}=\frac{\partial \mathrm{C}_{\mathrm{fw}}}{\partial \operatorname{Re}_{\mathrm{f}}} \cdot \frac{\partial}{\partial \mathrm{L}}\left[\frac{\mathrm{GD}}{\left[1-\mathrm{z}^{+2 / \mathrm{n}}\right] \mu_{1}}\right]$

$\therefore \frac{\partial \mathrm{C}_{\mathrm{fw}}}{\partial \mathrm{L}}=-\frac{\partial \mathrm{C}_{\mathrm{fw}}}{\partial \mathrm{Re}_{\mathrm{f}}} \cdot \frac{2 \mathrm{GD}\left(\mathrm{z}^{+}\right)^{\frac{2}{\mathrm{n}}} \mathrm{L}^{+}}{\mu_{1}\left\{1-\left(\mathrm{z}^{+}\right)^{\frac{2}{\mathrm{n}}}\right\}^{2} \mathrm{~L}_{\mathrm{he}} \mathrm{n}}$

$\therefore \frac{\partial \mathrm{I}_{1}}{\partial \mathrm{L}}=\int_{0}^{1-\mathrm{L}^{+}}\left[-\frac{\partial \mathrm{C}_{\mathrm{fw}}}{\partial \mathrm{Re}_{\mathrm{f}}} \cdot \frac{2 \mathrm{GD}\left(\mathrm{z}^{+}\right)^{\frac{2}{\mathrm{n}}} \mathrm{L}^{+}}{\mu_{1}\left\{1-\left(\mathrm{z}^{+}\right)^{\frac{2}{\mathrm{n}}}\right\}^{6} \mathrm{~L}_{\mathrm{he}} \mathrm{n}}+\mathrm{C}_{\mathrm{fw}} \frac{\partial}{\partial \mathrm{L}}\left\{1-\left(\mathrm{z}^{+}\right)^{\frac{2}{\mathrm{n}}}\right\}^{-4}\right] \mathrm{dz} \mathrm{z}^{+}+\frac{\mathrm{C}_{\mathrm{fw}}}{\mathrm{x}^{4}} \frac{\partial\left(1-\mathrm{L}^{+}\right)}{\partial \mathrm{L}}$

$\Rightarrow \frac{\partial \mathrm{I}_{1}}{\partial \mathrm{L}}=-\int_{0}^{1-\mathrm{L}^{+}}\left[\frac{\partial \mathrm{C}_{\mathrm{fw}}}{\partial \mathrm{Re}_{\mathrm{f}}} \cdot \frac{2 \mathrm{GD}\left(\mathrm{z}^{+}\right)^{\frac{2}{n}} \mathrm{~L}^{+}}{\mu_{1}\left\{1-\left(\mathrm{z}^{+}\right)^{\frac{2}{\mathrm{n}}}\right\}^{6} \mathrm{~L}_{\mathrm{he}} \mathrm{n}}+\frac{\mathrm{C}_{\mathrm{fw}} 8\left(\mathrm{z}^{+}\right)^{\frac{2}{n}} \mathrm{~L}^{+}}{\left\{1-\left(\mathrm{z}^{+}\right)^{\frac{2}{n}}\right\}^{5} \mathrm{~L}_{\mathrm{he}} \mathrm{n}}\right] \mathrm{dz}+\frac{\mathrm{C}_{\mathrm{fw}}}{\mathrm{x}^{4}} \frac{\partial\left(1-\mathrm{L}^{+}\right)}{\partial \mathrm{L}}$

Let, $\frac{\partial \mathrm{C}_{\mathrm{fw}}}{\partial \mathrm{Re}_{\mathrm{f}}} \cdot \frac{2 \mathrm{GD}\left(\mathrm{z}^{+}\right)^{\frac{2}{\mathrm{n}}} \mathrm{L}^{+}}{\mu_{1}\left\{1-\left(\mathrm{z}^{+}\right)^{\frac{2}{\mathrm{n}}}\right\}^{6} \mathrm{~L}_{\mathrm{he}} \mathrm{n}}=\mathrm{P}_{4}$ and, $\frac{\mathrm{C}_{\mathrm{fw}} 8\left(\mathrm{z}^{+}\right)^{\frac{2}{\mathrm{n}}} \mathrm{L}^{+}}{\left\{1-\left(\mathrm{z}^{+}\right)^{\frac{2}{\mathrm{n}}}\right\}^{5} \mathrm{~L}_{\mathrm{he}} \mathrm{n}}=\mathrm{P}_{5}$

$\therefore \frac{\partial \mathrm{I}_{1}}{\partial \mathrm{L}}=-\int_{0}^{1-\mathrm{L}^{+}}\left(\mathrm{P}_{4}+\mathrm{P}_{5}\right) \mathrm{dz}+\frac{\mathrm{C}_{\mathrm{fw}}}{\mathrm{x}^{4}} \cdot \frac{\partial\left(1-\mathrm{L}^{+}\right)}{\partial \mathrm{L}}$

Now, $\mathrm{I}_{2}=\int_{1-\mathrm{L}^{+}}^{1} \frac{\mathrm{C}_{\mathrm{fw}}\left(1-\mathrm{z}^{+}\right)^{2}}{\left\{1-\left(1-\mathrm{L}^{+}\right)^{2 / \mathrm{n}}\right\}^{2} \mathrm{~L}^{+2} \cdot\left\{1-\left(\mathrm{z}^{+}\right)^{2 / \mathrm{n}}\right\}^{2}} \mathrm{dz}$

$\Rightarrow \mathrm{I}_{2}=\int_{1-\mathrm{L}^{+}}^{1} \frac{\mathrm{C}_{\mathrm{fW}}\left(1-\mathrm{z}^{+}\right)^{2}}{\mathrm{~L}^{+2} \mathrm{X}^{+2} \cdot\left\{1-\left(\mathrm{z}^{+}\right)^{2 / \mathrm{n}}\right\}^{2}} \mathrm{dz}$

$\therefore \frac{\partial \mathrm{I}_{2}}{\partial \mathrm{L}}=\int_{1-\mathrm{L}^{+}}^{1} \frac{\partial}{\partial \mathrm{L}}\left[\frac{\mathrm{C}_{\mathrm{fw}}}{\mathrm{L}^{+2} \mathrm{x}^{2}}\right] \cdot \frac{\left(1-\mathrm{z}^{+}\right)^{2}}{\left\{1-\left(\mathrm{z}^{+}\right)^{2 / \mathrm{n}}\right\}^{2}} \mathrm{dz} \mathrm{z}^{+}-\frac{\mathrm{C}_{\mathrm{fw}}}{\mathrm{x}^{4}} \frac{\partial\left(1-\mathrm{L}^{+}\right)}{\partial \mathrm{L}}$ 
Here, $\frac{\partial}{\partial L}\left[\frac{C_{f w}}{L^{+2} x^{2}}\right]=$

$$
=\frac{\mathrm{L}^{+2} \mathrm{x}^{2} \frac{\partial \mathrm{C}_{\mathrm{fw}}}{\partial \mathrm{L}}-\mathrm{C}_{\mathrm{fw}}\left[\mathrm{L}^{+2} \cdot 2 \mathrm{x} \cdot(-1) \cdot \frac{2\left(1-\mathrm{L}^{+}\right)^{\frac{2}{\mathrm{n}}-1} \cdot \mathrm{L}^{+2}}{\mathrm{~L}_{\mathrm{he}} \cdot \mathrm{n}}+\mathrm{x}^{2} \cdot\left(-\frac{\mathrm{L}^{+3}}{\mathrm{~L}_{\mathrm{he}}}\right)\right]}{\left(\mathrm{L}^{+2} \mathrm{x}^{2}\right)^{2}}
$$

$\therefore \frac{\partial}{\partial \mathrm{L}}\left[\frac{\mathrm{C}_{\mathrm{fw}}}{\mathrm{L}^{+2} \mathrm{x}^{2}}\right]=\frac{\partial \mathrm{C}_{\mathrm{fw}}}{\partial \mathrm{L}} \cdot \frac{1}{\mathrm{~L}^{+2} \mathrm{x}^{2}}+\frac{\mathrm{C}_{\mathrm{fw}}}{\mathrm{L}_{\mathrm{he}} \cdot \mathrm{x}^{3}}\left[\frac{4\left(1-\mathrm{L}^{+}\right)^{\frac{2}{-1}}}{\mathrm{n}}+\frac{\mathrm{x}}{\mathrm{L}^{+}}\right]$

Let, $\frac{\mathrm{C}_{\mathrm{fw}}}{\mathrm{L}_{\mathrm{he}} \cdot \mathrm{X}^{3}}\left[\frac{4\left(1-\mathrm{L}^{+}\right)^{\frac{2}{\mathrm{n}}-1}}{\mathrm{n}}+\frac{\mathrm{x}}{\mathrm{L}^{+}}\right]=\mathrm{P}_{3}$

And,

$$
\begin{aligned}
& \frac{\partial}{\partial \mathrm{L}}\left[\left(1-\mathrm{z}^{+}\right)^{2} /\left[1-\left(\mathrm{z}^{+}\right)^{2 / \mathrm{n}}\right]^{2}\right]=\frac{\left[1-\left(\mathrm{z}^{+}\right)^{2 / \mathrm{n}}\right]^{2} \cdot \frac{\partial}{\partial \mathrm{L}}\left(1-\mathrm{z}^{+}\right)^{2}-\left(1-\mathrm{z}^{+}\right)^{2} \cdot \frac{\partial}{\partial \mathrm{L}}\left[1-\left(\mathrm{z}^{+}\right)^{2 / \mathrm{n}}\right]^{2}}{\left[1-\left(\mathrm{z}^{+}\right)^{2 / \mathrm{n}}\right]^{2}} \\
& =\frac{\left[2 \cdot\left\{1-\left(\mathrm{z}^{+}\right)^{2 / \mathrm{n}}\right\}^{2} \cdot\left(1-\mathrm{z}^{+}\right) \cdot \mathrm{z}^{+} \cdot \mathrm{L}^{+} / \mathrm{L}_{\mathrm{he}}\right]-\left[4 \cdot\left(1-\mathrm{z}^{+}\right)^{2} \cdot\left\{1-\left(\mathrm{z}^{+}\right)^{2 / \mathrm{n}}\right\} \cdot\left(\mathrm{z}^{+}\right)^{2 / \mathrm{n}} \mathrm{L}^{+} / \mathrm{n} \cdot \mathrm{L}_{\mathrm{he}}\right]}{\left[1-\left(\mathrm{z}^{+}\right)^{2 / \mathrm{n}}\right]^{4}} \\
& \therefore \frac{\partial}{\partial \mathrm{L}}\left\{\left(1-\mathrm{z}^{+}\right)^{2} /\left[1-\left(\mathrm{z}^{+}\right)^{2 / \mathrm{n}}\right]^{2}\right\}=\frac{2\left(1-\mathrm{z}^{+}\right) \mathrm{z}^{+} \mathrm{L}^{+}}{\left[1-\left(\mathrm{z}^{+}\right)^{2 / \mathrm{n}}\right]^{2} \cdot \mathrm{L}_{\mathrm{he}}}-\frac{4\left(1-\mathrm{z}^{+}\right)^{2} \cdot\left(\mathrm{z}^{+}\right)^{\frac{2}{\mathrm{n}}} \mathrm{L}^{+}}{\left[1-\left(\mathrm{z}^{+}\right)^{2 / \mathrm{n}}\right]^{3} \cdot \mathrm{n} \cdot \mathrm{L}_{\mathrm{he}}}=\mathrm{P}_{2} \\
& \therefore \frac{\partial \mathrm{I}_{2}}{\partial \mathrm{L}}=\int_{1-\mathrm{L}^{+}}^{1}\left[\left[\left\{\frac{\partial \mathrm{C}_{\mathrm{fw}}}{\partial \mathrm{L}} \cdot \frac{1}{\mathrm{~L}^{+2} \mathrm{x}^{2}}+\frac{\mathrm{C}_{\mathrm{fw}}}{\mathrm{L}^{+2} \mathrm{x}^{2}}\left(\frac{4\left(1-\mathrm{L}^{+}\right)^{(2 / \mathrm{n})-1}}{\mathrm{n}}-\frac{\mathrm{x}}{\mathrm{L}^{+}}\right)\right\} \cdot \frac{\left(1-\mathrm{z}^{+}\right)^{2}}{\left\{1-\left(\mathrm{z}^{+}\right)^{2 / \mathrm{n}}\right\}^{2}}\right]\right. \\
& +\left[\frac{C_{f w}}{L^{+2} x^{2}}\left\{\frac{2\left(1-z^{+}\right) z^{+} L^{+}}{\left\{1-\left(z^{+}\right)^{2 / n}\right\}^{2} L_{h e}}-\frac{4\left(1-z^{+}\right)\left(z^{+}\right)^{\frac{2}{n}} L^{+}}{\left\{1-\left(z^{+}\right)^{2 / n}\right\}^{3} \cdot n \cdot L_{h e}}\right\}\right. \\
& \left.+\frac{\mathrm{C}_{\mathrm{fw}}}{\mathrm{L}^{+2} \mathrm{x}^{2}}\left(\frac{4\left(1-\mathrm{L}^{+}\right)^{\frac{2}{\mathrm{n}}-1}}{\mathrm{n}}-\frac{\mathrm{x}}{\mathrm{L}^{+}}\right)\right] \mathrm{dz^{+ }}-\frac{\mathrm{C}_{\mathrm{fw}}}{\mathrm{x}^{4}} \cdot \frac{\partial\left(1-\mathrm{L}^{+}\right)}{\partial \mathrm{L}}
\end{aligned}
$$

Again, $\frac{\partial \mathrm{C}_{\mathrm{fw}}}{\partial \mathrm{L}}=\frac{\partial \mathrm{C}_{\mathrm{fw}}}{\partial \mathrm{Re}_{\mathrm{f}}} \cdot \frac{\partial \mathrm{Re}_{\mathrm{f}}}{\partial \mathrm{L}}$

Here, $\frac{\partial \operatorname{Re}_{\mathrm{f}}}{\partial \mathrm{L}}=\frac{\partial}{\partial \mathrm{L}}\left\{\frac{\mathrm{GD}\left(1-\mathrm{z}^{+}\right)}{\left[1-\left(1-\mathrm{L}^{+}\right)^{2 / \mathrm{n}}\right]^{2} \mu_{1} \cdot \mathrm{L}^{+}}\right\} \cdot \Rightarrow \frac{\partial \mathrm{Re}_{\mathrm{f}}}{\partial \mathrm{L}}=\frac{\mathrm{GD}}{\mu_{1}} \cdot\left[\frac{1}{\mathrm{xL}}+\frac{\left(1-\mathrm{z}^{+}\right) \cdot 2 \cdot\left(1-\mathrm{L}^{+}\right)^{\frac{2}{\mathrm{n}}-1} \mathrm{~L}^{+}}{\mathrm{xL} \mathrm{L}_{\mathrm{he}} \cdot \mathrm{n}}\right]$

$\therefore \frac{\partial \mathrm{C}_{\mathrm{fw}}}{\partial \mathrm{L}}=\frac{\partial \mathrm{C}_{\mathrm{fw}}}{\partial \mathrm{Re}_{\mathrm{f}}} \cdot \frac{\mathrm{GD}}{\mu_{1}} \cdot\left[\frac{1}{\mathrm{xL}_{\mathrm{he}}}+\frac{2 \cdot\left(1-\mathrm{z}^{+}\right) \cdot\left(1-\mathrm{L}^{+}\right)^{\frac{2}{\mathrm{n}}-1} \mathrm{~L}^{+}}{\mathrm{xL} \mathrm{L}_{\mathrm{he}} \cdot \mathrm{n}}\right]=\mathrm{P}_{1}$

$\therefore \frac{\partial \mathrm{I}_{2}}{\partial \mathrm{L}}=\int_{1-\mathrm{L}^{+}}^{1}\left[\left(\frac{\mathrm{P}_{1}}{\mathrm{~L}^{+2} \mathrm{x}^{2}}+\mathrm{P}_{3}\right) \cdot \frac{\left(1-\mathrm{z}^{+}\right)^{2}}{\left[1-\left(\mathrm{z}^{+}\right)^{2 / \mathrm{n}}\right]^{2}}+\mathrm{P}_{2} \cdot \frac{\mathrm{C}_{\mathrm{fw}}}{\mathrm{L}^{+2} \mathrm{x}^{2}}\right] \mathrm{dz}+\frac{\mathrm{C}_{\mathrm{fw}}}{\mathrm{x}^{4}} \cdot \frac{\partial\left(1-\mathrm{L}^{+}\right)}{\partial \mathrm{L}}$

Let, 


$$
\begin{aligned}
& \left(\frac{\mathrm{P}_{1}}{\mathrm{~L}^{+2} \mathrm{x}^{2}}+\mathrm{P}_{3}\right) \cdot \frac{\left(1-\mathrm{z}^{+}\right)^{2}}{\left[1-\left(\mathrm{z}^{+}\right)^{2 / \mathrm{n}}\right]^{2}}=\mathrm{P}_{6} \\
& \mathrm{P}_{2} \cdot \frac{\mathrm{C}_{\mathrm{fw}}}{\mathrm{L}^{+2} \mathrm{x}^{2}}=\mathrm{P}_{7} \\
& \therefore \frac{\partial \mathrm{I}_{2}}{\partial \mathrm{L}}=\int_{1-\mathrm{L}^{+}}^{1}\left(\mathrm{P}_{6}+\mathrm{P}_{7}\right) \mathrm{dz}-\frac{\mathrm{C}_{\mathrm{fw}}}{\mathrm{x}^{4}} \cdot \frac{\partial\left(1-\mathrm{L}^{+}\right)}{\partial \mathrm{L}} \\
& \therefore \frac{\partial \mathrm{I}}{\partial \mathrm{L}}=-\int_{0}^{1-\mathrm{L}^{+}}\left(\mathrm{P}_{4}+\mathrm{P}_{5}\right) \mathrm{dz}^{+}+\int_{1-\mathrm{L}^{+}}^{1}\left(\mathrm{P}_{6}+\mathrm{P}_{7}\right) \mathrm{dz}^{+}
\end{aligned}
$$

\section{For $\mathbf{L}=\mathbf{L}_{\mathrm{he}}$}

$\mathrm{F}_{\mathrm{w}}=\pi \mathrm{r}_{0} \rho_{1} \mathrm{~L} \int_{0}^{1} \mathrm{C}_{\mathrm{fw}} \frac{\mathrm{j}_{1}{ }^{2}}{\left[1-\left(\mathrm{z}^{+}\right)^{2 / \mathrm{n}}\right]^{2}} \mathrm{dz} \mathrm{z}^{+}$and $\mathrm{j}_{\mathrm{l}}=\frac{\mathrm{G}\left(1-\mathrm{z}^{+}\right)}{\rho_{\mathrm{l}}}$

$\therefore \mathrm{F}_{\mathrm{w}}=\pi \mathrm{r}_{0} \rho_{1} \mathrm{~L} \int_{0}^{1} \mathrm{C}_{\mathrm{fw}} \frac{\mathrm{G}^{2}\left(1-\mathrm{z}^{+}\right)^{2}}{\left[1-\left(\mathrm{z}^{+}\right)^{2 / \mathrm{n}}\right]^{2}} \mathrm{dz}^{+}$and $\Rightarrow \mathrm{F}_{\mathrm{w}}=\frac{\pi \mathrm{r}_{0} \mathrm{G}^{2} \mathrm{~L}}{\rho_{\mathrm{l}}}$.I

Where $\mathrm{I}=\int_{0}^{1} \mathrm{C}_{\mathrm{fw}} \frac{\left(1-\mathrm{z}^{+}\right)^{2}}{\left[1-\left(\mathrm{z}^{+}\right)^{2 / \mathrm{n}}\right]^{2}} \mathrm{dz}$ and $\therefore \frac{\partial \mathrm{I}}{\partial \mathrm{L}}=\frac{\partial}{\partial \mathrm{L}} \int_{0}^{1} \mathrm{C}_{\mathrm{fw}} \frac{\left(1-\mathrm{z}^{+}\right)^{2}}{\left[1-\left(\mathrm{z}^{+}\right)^{2 / \mathrm{n}}\right]^{2}} \mathrm{dz}^{+}$

Applying Leibniz Integral rule, we get

$$
\frac{\partial \mathrm{I}}{\partial \mathrm{L}}=\int_{0}^{1}\left[\frac{\partial \mathrm{C}_{\mathrm{fw}}}{\partial \mathrm{L}} \cdot \frac{\left(1-\mathrm{z}^{+}\right)^{2}}{\left[1-\left(\mathrm{z}^{+}\right)^{2 / \mathrm{n}}\right]^{2}}+\mathrm{C}_{\mathrm{fw}} \frac{\partial}{\partial \mathrm{L}} \frac{\left(1-\mathrm{z}^{+}\right)^{2}}{\left[1-\left(\mathrm{z}^{+}\right)^{2 / \mathrm{n}}\right]^{2}} \mathrm{dz}^{+}\right]
$$

Now, $\frac{\partial \mathrm{C}_{\mathrm{fw}}}{\partial \mathrm{L}}=\frac{\partial \mathrm{C}_{\mathrm{fw}}}{\partial \mathrm{Re}_{\mathrm{f}}} \cdot \frac{\partial \mathrm{Re}_{\mathrm{f}}}{\partial \mathrm{L}}, \frac{\partial \mathrm{C}_{\mathrm{fw}}}{\partial \mathrm{L}}=\frac{\partial \mathrm{C}_{\mathrm{fw}}}{\partial \mathrm{Re}_{\mathrm{f}}} \cdot \frac{\mathrm{GD}}{\mu_{1}} \cdot\left(\frac{\mathrm{z}^{+} \mathrm{L}^{+}}{\mathrm{L}_{\mathrm{he}}}\right)$

We have $\frac{\partial}{\partial \mathrm{L}}\left\{\frac{\left(1-\mathrm{z}^{+}\right)^{2}}{\left[1-\left(\mathrm{z}^{+}\right)^{2 / \mathrm{n}}\right]^{2}}\right\}=\mathrm{P}_{2} . \therefore \frac{\partial \mathrm{I}}{\partial \mathrm{L}}=\int_{0}^{1}\left[\left\{\frac{\partial \mathrm{C}_{\mathrm{fw}}}{\partial \mathrm{L}} \cdot \frac{\mathrm{GD}}{\mu_{1}} \cdot\left(\frac{\mathrm{z}^{+} \mathrm{L}^{+}}{\mathrm{L}_{\mathrm{he}}}\right) \cdot \frac{\left(1-\mathrm{z}^{+}\right)^{2}}{\left[1-\left(\mathrm{z}^{+}\right)^{2 / \mathrm{n}}\right]^{2}}\right\}+\left(\mathrm{C}_{\mathrm{fw}}\right) \cdot \mathrm{P}_{2}\right] \mathrm{dz} \mathrm{z}^{+}$

Let, $\frac{\partial \mathrm{C}_{\mathrm{fw}}}{\partial \mathrm{L}} \cdot \frac{\mathrm{GD}}{\mu_{1}} \cdot\left(\frac{\mathrm{z}^{+} \mathrm{L}^{+}}{\mathrm{L}_{\mathrm{he}}}\right) \cdot \frac{\left(1-\mathrm{z}^{+}\right)^{2}}{\left[1-\left(\mathrm{z}^{+}\right)^{2 / \mathrm{n}}\right]^{2}}=\mathrm{P}_{8} \cdot \therefore \frac{\partial \mathrm{I}}{\partial \mathrm{L}}=\int_{0}^{1}\left[\left(\mathrm{P}_{8}\right)+\left(\mathrm{C}_{\mathrm{fw}} \cdot \mathrm{P}_{2}\right)\right] \mathrm{dz}$

\section{For, $\mathbf{L}<\mathbf{L}_{\text {he }}$}

$$
\mathrm{F}_{\mathrm{w}}=\pi \mathrm{r}_{0} \operatorname{L} \rho_{1} \int_{0}^{1} \mathrm{C}_{\mathrm{fw}} \frac{\mathrm{j}_{1}^{2}}{\left[1-\left(\mathrm{z}^{+}\right)^{2 / \mathrm{n}}\right]^{2}} \mathrm{dz}
$$

We have, $j_{1}=\frac{G\left(1-z^{+}\right)}{\rho_{1} L^{+}}$

$\therefore \mathrm{F}_{\mathrm{w}}=\pi \mathrm{r}_{0} \rho_{1} \mathrm{~L} \int_{0}^{1} \mathrm{C}_{\mathrm{fw}} \frac{\mathrm{G}^{2}\left(1-\mathrm{z}^{+}\right)^{2}}{\left[1-\left(\mathrm{z}^{+}\right)^{2 / \mathrm{n}}\right]^{2}} \mathrm{dz}$

Where,

$$
\mathrm{I}=\int_{0}^{1} \mathrm{C}_{\mathrm{fw}} \frac{\left(1-\mathrm{z}^{+}\right)^{2}}{\mathrm{~L}^{+2}\left[1-\left(\mathrm{z}^{+}\right)^{2 / \mathrm{n}}\right]^{2}} \mathrm{dz} \mathrm{z}^{+} . \therefore \frac{\partial \mathrm{I}}{\partial \mathrm{L}}=\int_{0}^{1}\left[\frac{\partial}{\partial \mathrm{L}}\left(\frac{\mathrm{C}_{\mathrm{fw}}}{\mathrm{L}^{+2}}\right)\left\{\frac{\left(1-\mathrm{z}^{+}\right)^{2}}{\left[1-\left(\mathrm{z}^{+}\right)^{2 / \mathrm{n}}\right]^{2}}\right\}+\left\{\frac{\mathrm{C}_{\mathrm{fw}}}{\mathrm{L}^{+2}} \cdot \frac{(1-1)^{2}}{\left[1-(1)^{2 / \mathrm{n}}\right]^{2}}\right\}\right] \mathrm{dz}
$$

Here, $\frac{\partial}{\partial \mathrm{L}}\left(\frac{\mathrm{C}_{\mathrm{fw}}}{\mathrm{L}^{+2}}\right)=\frac{2 \mathrm{C}_{\mathrm{fw}}}{\mathrm{L}^{+3}} \cdot \frac{\partial \mathrm{L}^{+2}}{\partial \mathrm{L}_{\mathrm{he}}}+\frac{1}{\mathrm{~L}^{+2}} \cdot\left(\frac{\partial \mathrm{C}_{\mathrm{fw}}}{\partial \mathrm{Re}_{\mathrm{f}}} \cdot \frac{\partial \mathrm{Re}_{\mathrm{f}}}{\partial \mathrm{L}}\right)$ 
We have, $\operatorname{Re}_{\mathrm{f}}=\frac{\mathrm{GD}\left(1-\mathrm{z}^{2}\right)}{\mu_{1}} . \therefore \frac{\partial \mathrm{Re}_{\mathrm{f}}}{\partial \mathrm{L}}=\frac{\mathrm{GD}}{\mu_{1}} \cdot \frac{\partial}{\partial \mathrm{L}}\left(\frac{1-\mathrm{z}^{+}}{\mathrm{L}^{+}}\right)$and $\therefore \frac{\partial}{\partial \mathrm{L}}\left(\frac{\mathrm{C}_{\mathrm{fw}}}{\mathrm{L}^{+2}}\right)=\frac{2 \mathrm{C}_{\mathrm{fw}}}{\mathrm{L}^{+} \mathrm{L}_{\mathrm{he}}}+\frac{1}{\mathrm{~L}^{+2}}\left(\frac{\partial \mathrm{C}_{\mathrm{fw}}}{\partial \mathrm{Re}_{\mathrm{f}}} \cdot \frac{\mathrm{GD}}{\mu_{1} \mathrm{~L}_{\mathrm{he}}}\right)$

Let, $\frac{2 \mathrm{C}_{\mathrm{fw}}}{\mathrm{L}^{+} \mathrm{L}_{\mathrm{he}}}+\frac{1}{\mathrm{~L}^{+2}}\left(\frac{\partial \mathrm{C}_{\mathrm{fw}}}{\partial \mathrm{Re}_{\mathrm{f}}} \cdot \frac{\mathrm{GD}}{\mu_{1} \mathrm{~L}_{\mathrm{he}}}\right)=\mathrm{q}_{1}$. so, $\frac{\partial \mathrm{I}}{\partial \mathrm{L}}=\int_{0}^{1}\left[\mathrm{q}_{1} \cdot \frac{\left(1-\mathrm{z}^{+}\right)^{2}}{\left[1-\left(\mathrm{z}^{+}\right)^{2 / \mathrm{n}}\right]^{2}}+\frac{\mathrm{C}_{\mathrm{fw}}}{\mathrm{L}^{+2}} \cdot \mathrm{P}_{2}\right] \mathrm{dz}^{+}$

Let, $\mathrm{q}_{1} \cdot \frac{\left(1-\mathrm{z}^{+}\right)^{2}}{\left[1-\left(\mathrm{z}^{+}\right)^{2 / \mathrm{n}}\right]^{2}}=\mathrm{q}_{2}$ and, $\frac{\mathrm{C}_{\mathrm{fw}}}{\mathrm{L}^{+2}} \cdot \mathrm{P}_{2}=\mathrm{q}_{3} \therefore \frac{\partial \mathrm{I}}{\partial \mathrm{L}}=\int_{0}^{1}\left(\mathrm{q}_{2}+\mathrm{q}_{3}\right) \mathrm{dz}^{+}$

Hence the frictional force becomes $F_{w}=\frac{\pi r_{0} G^{2} L}{\rho_{1}}$.I

where,

$$
\begin{aligned}
& I=\left[\int_{0}^{1-L^{+}} \frac{C_{f w}}{\left\{1-\left(z^{+}\right)^{2 / n}\right\}^{4}} d z^{+}+\int_{1-L^{+}}^{1} \frac{C_{f w}\left(1-z^{+}\right)^{2}}{\left\{1-\left(1-L^{+}\right)^{2 / n}\right\}^{2} L^{+2} \cdot\left\{1-\left(z^{+}\right)^{2 / n}\right\}^{2}} d z^{+}\right], \quad \text { for } L^{+}<1 \\
& =\int_{0}^{1} C_{\mathrm{fw}} \frac{\left(1-\mathrm{z}^{+}\right)^{2}}{\left[1-\left(\mathrm{z}^{+}\right)^{2 / \mathrm{n}}\right]^{2}} \mathrm{dz}, \\
& =\int_{0}^{1} \mathrm{C}_{\mathrm{fw}} \frac{\left(1-\mathrm{z}^{+}\right)^{2}}{\mathrm{~L}^{+2}\left[1-\left(\mathrm{z}^{+}\right)^{2 / \mathrm{n}}\right]^{2}} \mathrm{dz}^{+}, \\
& \text {for } L^{+}=1 \\
& \text { for } \mathrm{L}^{+}>1
\end{aligned}
$$

